\title{
Microstructure of Interpass Rolled Wire + Arc Additive Manufacturing Ti-6Al-4V Components
}

\author{
FILOMENO MARTINA, PAUL A. COLEGROVE, STEWART W. WILLIAMS, \\ and JONATHAN MEYER
}

\begin{abstract}
Mechanical property anisotropy is one of the issues that are limiting the industrial adoption of additive manufacturing (AM) Ti-6Al-4V components. To improve the deposits' microstructure, the effect of high-pressure interpass rolling was evaluated, and a flat and a profiled roller were compared. The microstructure was changed from large columnar prior $\beta$ grains that traversed the component to equiaxed grains that were between 56 and $139 \mu \mathrm{m}$ in size. The repetitive variation in Widmanstätten $\alpha$ lamellae size was retained; however, with rolling, the overall size was reduced. A "fundamental study" was used to gain insight into the microstructural changes that occurred due to the combination of deformation and deposition. High-pressure interpass rolling can overcome many of the shortcomings of AM, potentially aiding industrial implementation of the process.
\end{abstract}

DOI: $10.1007 / \mathrm{s} 11661-015-3172-1$

(C) The Author(s) 2015. This article is published with open access at Springerlink.com

\section{INTRODUCTION}

ADDITIVE manufacturing (AM) is a fabrication technique in which a structure is created by depositing successive layers. This approach enables substantial material savings, compared to subtractive techniques such as machining: in the aerospace sector, buy-to-fly ratios (the ratio of the weight of the initial workpiece to the one of the finished part) can be as high as $30,{ }^{11}$ while in $\mathrm{AM}$, this can be potentially reduced to around 1.5 or lower. ${ }^{[2]}$ The high cost of titanium production and machining has been the main motivation for the large number of investigations into AM methods.

Wire + arc additive manufacturing (WAAM) uses metal in the form of wire in combination with an arc, ${ }^{[3]}$ and can be based on either Tungsten inert gas (TIG),$^{[4,5]}$ plasma ${ }^{[2]}$ or metal inert gas welding. ${ }^{[6]}$ The microstructures of Ti-6Al-4V produced by WAAM can be either Widmanstätten or martensitic which depends not on the cooling rate of the first cycle after the material is deposited, but on the peak temperature and cooling rate when the subsequent layers are deposited. ${ }^{[2]}$ The prior $\beta$ grains are equiaxed near the substrate; however, further away epitaxial growth results in large columnar grains that traverse the deposited layers. These grains grow opposite to the heat flow and are highly textured, leading to anisotropic mechanical properties. ${ }^{[4]}$

High-pressure rolling, originally developed for welding ${ }^{[7]}$ is a local mechanical stretching method in which a

FILOMENO MARTINA, Research Fellow, PAUL A. COLEGROVE, Senior Lecturer, and STEWART W. WILLIAMS, Professor, are with the Welding Engineering and Laser Processing Centre, Cranfield University, Building 46, Bedfordshire MK43 0AL, U.K. Contact e-mail: f.martina@ cranfield.ac.uk JONATHAN MEYER, Research Engineer, is with Airbus Group Innovation, 20A1 Building, New Filton House, Bristol, BS99 7AR, U.K.

Manuscript submitted October 22, 2014.

Article published online October 13, 2015 load is applied with a moving roller. If the load is sufficient to compress plastically the bead in the normal direction, a plastic stretching will occur in the rolling direction, thus decreasing the longitudinal residual stresses. $^{[8]}$ When applied to steel WAAM structures, rolling resulted in a reduction of the grain size, due to the enhanced recrystallization that occurred with the deposition of the subsequent layer on the plastically deformed component. ${ }^{[9]}$ Rolling of Ti-6Al-4V WAAM structures was initially presented, ${ }^{[10,11]}$ and will be discussed in depth in this paper.

\section{EXPERIMENTS}

The experiments were performed on a custom-made rolling rig, equipped with a Lincoln Electric Invertec V310-T AC/DC TIG power supply. A schematic view of the setup is shown in Figure 1(a) (the $X, Y$, and $Z$ directions are defined in this figure). The parameters for the pulsed TIG process, which are presented in Table I, produced a wall width of $6 \mathrm{~mm}$. Aerospace grade 5 Ti-6Al-4V welding wire was provided by VBC Group; its chemical composition was taken from the material certificate and is shown in Table II.

\section{A. Evaluation of Strain and Microstructure}

These experiments were used to characterize the microstructure of WAAM samples that were rolled between depositing layers. Baseplates which were 405- $\mathrm{mm}$ long, $60-\mathrm{mm}$ wide, and 6-mm thick were clamped by screws along each side of the plate (Figure 1(b)). Six walls were built: a "control" left in the as-deposited condition; three samples that used a "profiled" roller with loads of 50, 75, and $100 \mathrm{kN}$, and two that used a roller with a flat profile and loads of 50 


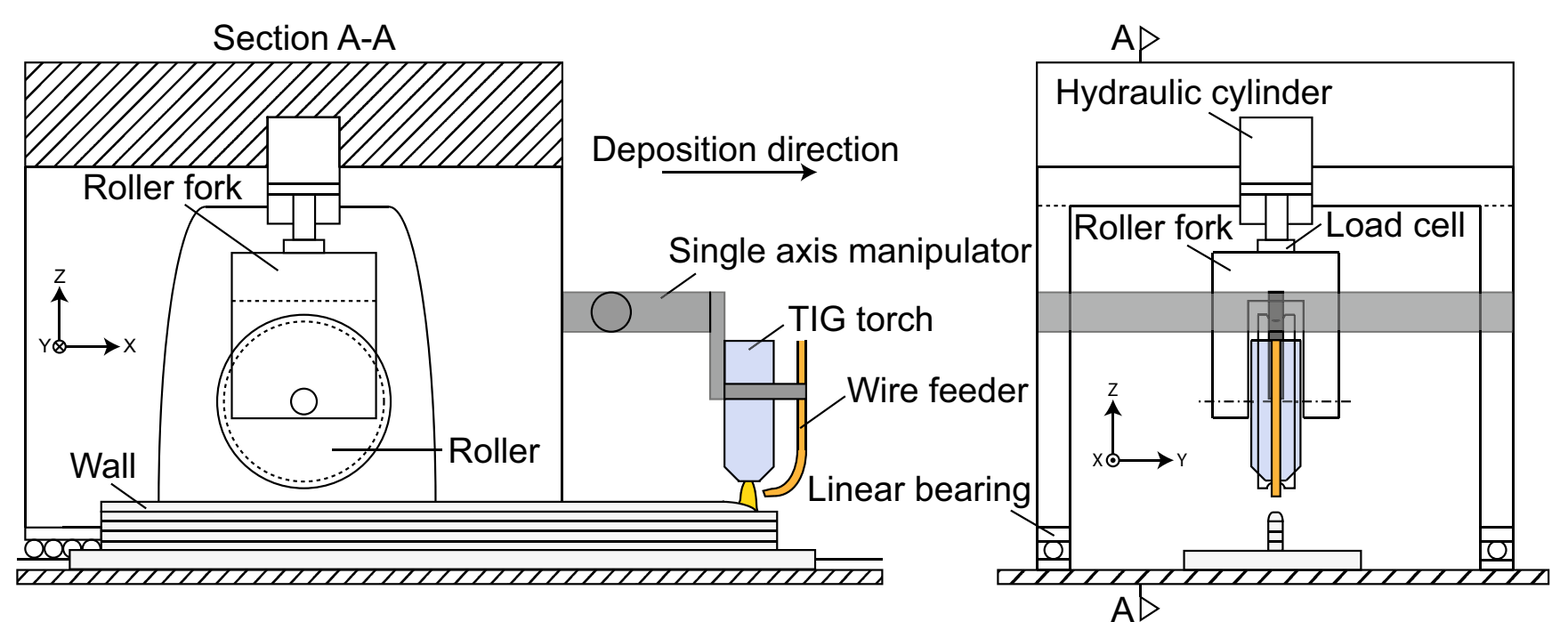

(a)

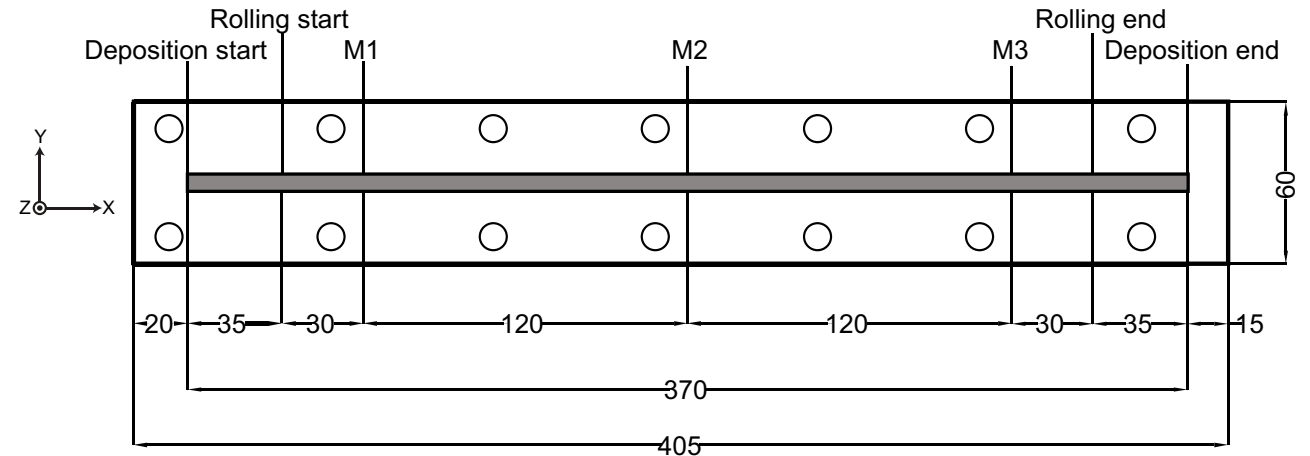

(b)

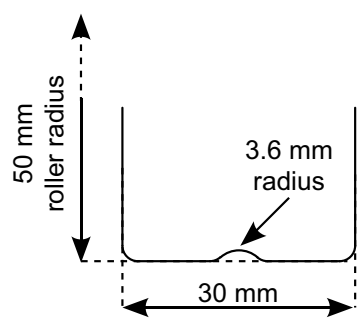

(c)

Fig. 1-Experimental setup for rolling investigation: $(a)$ schematic of experimental setup, $(b)$ details of base plate including holes for clamping, and $(c)$ dimensions of the roller.

Table I. Deposition Parameters

\section{Wire feed speed}

Travel speed

Peak current

Background current

Average current

Pulse duration

Frequency

Gas flow rate

Trailing shield gas flow rate

Electrode to workpiece distance

and $75 \mathrm{kN}$. Rolling loads were chosen on the basis of previous work on steel, ${ }^{[9]}$ and considering the higher strength of Ti-6Al-4V. A sample was produced with a $100 \mathrm{kN}$ rolling load; however, it fractured at the interface between the wall and the substrate after rolling the seventh layer.

The "profiled" roller's shape approximately conformed to the profile of the deposit as shown in Figure 1(c). Both rollers were made of case-hardened $\mathrm{H} 13$ tool steel and a rolling speed of $3 \mathrm{~mm} \mathrm{~s}^{-1}$ was used. Layer deposition and rolling application were alternated, and the part was allowed to cool to room temperature, before rolling was applied. Deposition started $20 \mathrm{~mm}$ from the end of the baseplate and stopped $15 \mathrm{~mm}$ from the other end (Figure 1(b)), giving a total wall length of $370 \mathrm{~mm}$. Rolling began and ended $35 \mathrm{~mm}$ from the ends of the deposit.

The layer height ( $\mathrm{LH})$ from the baseplate was measured with a digital vernier at three points labeled M1, M2, and M3 $\left(l h_{i, j}\right)$ which are indicated in Figure 1(b),

Table II. Chemical Composition of Ti-6Al-4V Wire Used in the Experiments

\begin{tabular}{lccccccccccc}
\hline Ti & Al & V & Fe & O & C & N & H & TOE & Y & Others \\
\hline Bal. & 6.08 & 4 & 0.18 & 0.16 & 0.035 & 0.011 & 0.0017 & $<0.2$ & $<0.001$ & $<0.05$ \\
\hline
\end{tabular}


before and after rolling; $i$ indicates the layer number, and $j$ the point of measurement. The height of each layer $\left(\mathrm{LH}_{i}\right)$, and mean $\mathrm{LH}(\overline{\mathrm{LH}})$ were calculated from:

$$
\begin{gathered}
\mathrm{LH}_{i}=\left(\frac{1}{3} \sum_{j=1}^{3} l h_{i, j}\right)-\left(\frac{1}{3} \sum_{j=1}^{3} l h_{i-1, j}\right) \\
\overline{\mathrm{LH}}=\frac{1}{16} \sum_{i=5}^{20} \mathrm{LH}_{i}
\end{gathered}
$$

The first four layers were excluded from the calculation of the overall LH due to the thermal effect of the baseplate which reduced the deposit wall width and increased the $\mathrm{LH}^{\left[{ }^{[2]}\right.}$

The average total engineering strains $\left(\epsilon_{y}\right.$ and $\left.\epsilon_{z}\right)$ introduced by rolling were calculated in terms of the fractional difference between the unrolled and rolled wall widths (for $\epsilon_{y}$ ) and LHs (for $\epsilon_{z}$ ), respectively. The semi-automatic nature of the manipulating system, combined with the manual start and stop of the welding arc, resulted in small inaccuracies in the length of the deposits. Consequently, the change in the deposits' length $\left(\epsilon_{x}\right)$ could not be assessed.

Cross-section specimens were extracted from the XY, $\mathrm{XZ}$ and $\mathrm{YZ}$ planes, at the mid point of each wall. These sections were mounted in resin, ground, polished and etched with a solution of hydrofluoric acid for optical microscopy imaging. Images taken from the center of the specimens extracted from the YZ plane were used for prior grain size measurement, which was done with the the linear intercept method. ${ }^{[12]}$ For each image, five measurements were taken for three directions $(0,45$, and $90 \mathrm{deg}$ line orientations) giving a total of 15 measurements per sample.

The thickness of $\alpha$ lamellae in the samples produced with the profiled roller was measured using five scanning electron microscope (SEM) images according to the method explained in Tiley et al. ${ }^{[13]}$ Each image corresponded to a specific location within a generic band, as

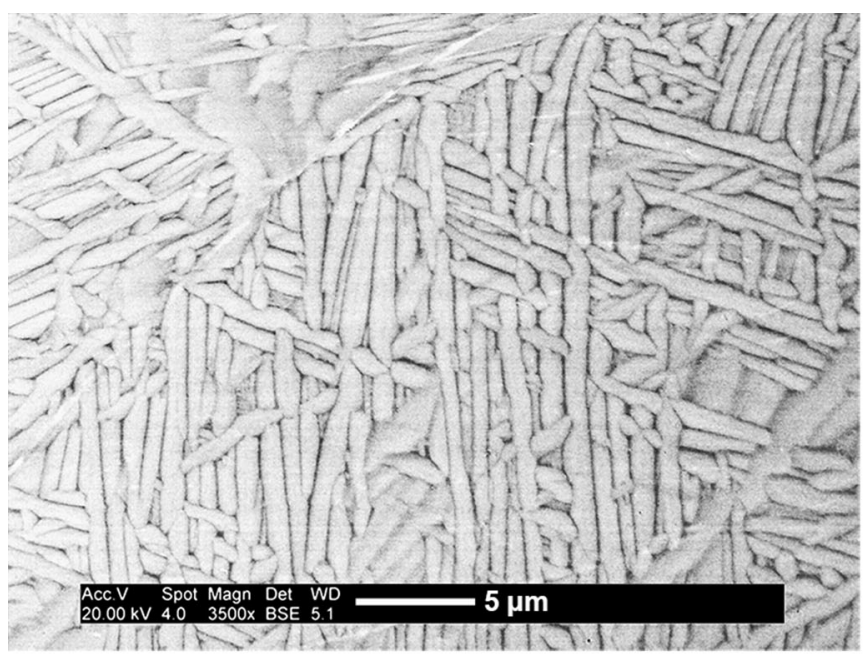

(a)

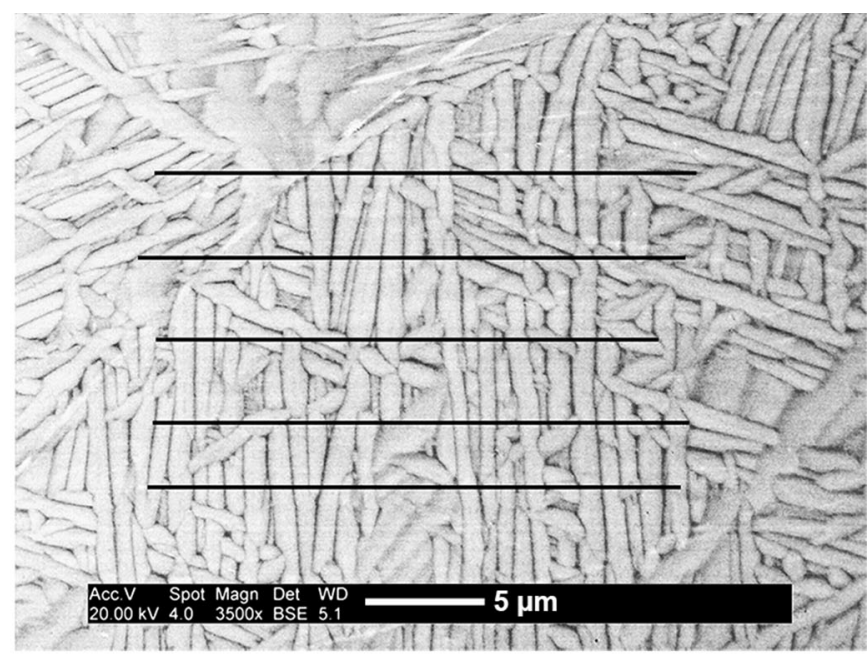

(b)

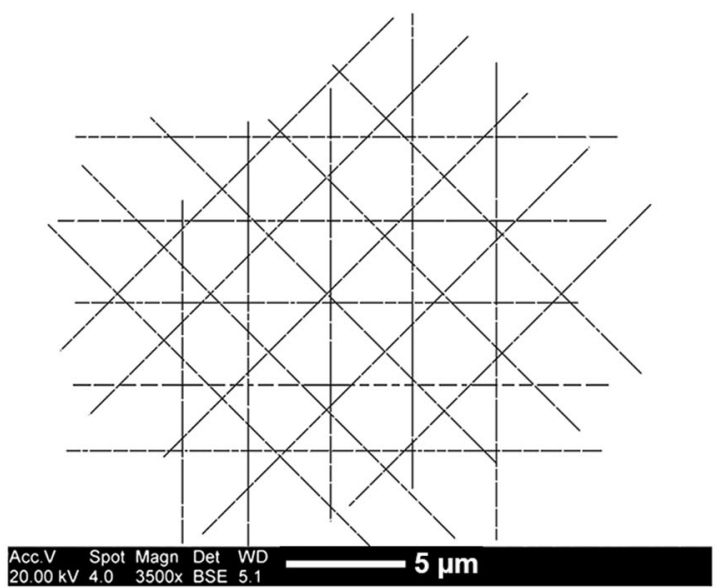

(d)

(c)

Fig. 2-Semi-automatic method to measure the thickness of the $\alpha$ laths, as described in Tiley et al. ${ }^{[13]}(a)$ shows as an example the original image taken from location $\mathrm{C}$ of the specimen rolled at $75 \mathrm{kN}$. (b) shows five lines of known length with 0 deg inclination. $(c)$ shows the lines broken where they intercept $\alpha$ phase boundaries. (d) shows the full set of lines oriented with $0,45,90$, and 135 deg inclinations. 
described in Martina et al. ${ }^{[2]}$ Prior to the SEM investigation, the samples were re-polished for eight minutes at $100 \mathrm{~kg} / \mathrm{m}^{2}$ and $80 \mathrm{rpm}$. SEM images were taken using a backscatter detector, a voltage of $20 \mathrm{keV}$, and a spot size of four (Figure 2(a)). The images were processed with Adobe Photoshop CS4. ${ }^{[14]}$ For each image, five lines were drawn to give five sets of measurements for a particular direction (Figure 2(b)). The lines were divided where they intercepted the boundaries of $\alpha$ phase laths (Figure 2(c)). This was repeated for four directions (0, 45 , 90, and 135 deg orientations) giving 20 measurements per location (Figure 2(d)), in accordance with
ASTM E1382, ${ }^{[15]}$ to take into account the strong anisotropy of the microstructure. The length of the intercepts across each line was determined using the ImageJ software ${ }^{[16]}$ and its plugin Measure Roi PA. ${ }^{[17]}$ Finally, the $\alpha$ lamellae thickness was determined as $1 / 1.5(1 / \lambda)_{\text {mean }}{ }^{[13]}$ where $\lambda_{\text {mean }}$ is the mean intercept length.

\section{B. Fundamental Study}

The fundamental study was used to understand separately the factors that influence the microstructural

Table III. Average Engineering Strains (Pct)

\begin{tabular}{lrrrrr}
\hline & \multicolumn{3}{c}{ Profiled Roller } & \multicolumn{2}{c}{ Flat Roller } \\
\cline { 2 - 6 } & \multicolumn{1}{c}{$\epsilon_{z}$} & $\epsilon_{y}$ & $\epsilon_{z}$ & $\epsilon_{y}$ \\
\hline $50 \mathrm{kN}$ & 7.9 & -8.1 & 4.4 & -6.8 \\
$75 \mathrm{kN}$ & 18.2 & -17.5 & 15.0 & -20.3 \\
\hline
\end{tabular}

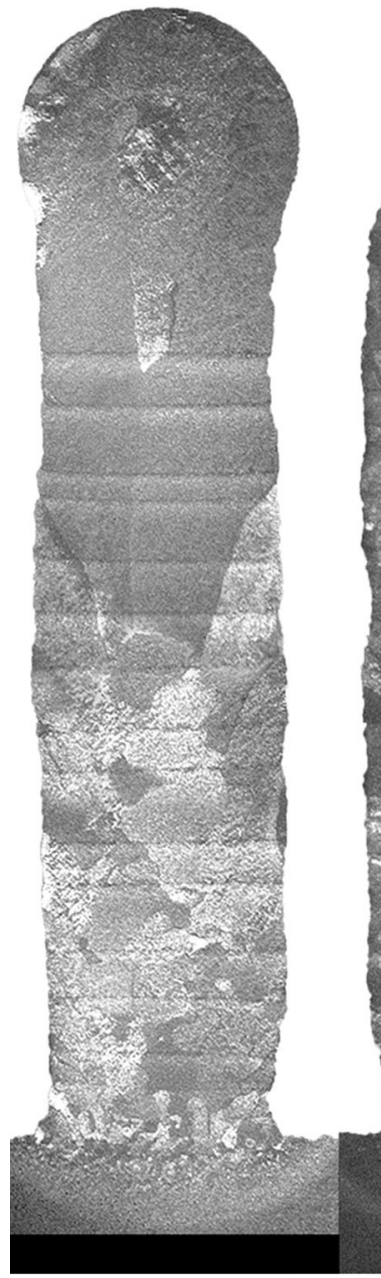

(a)

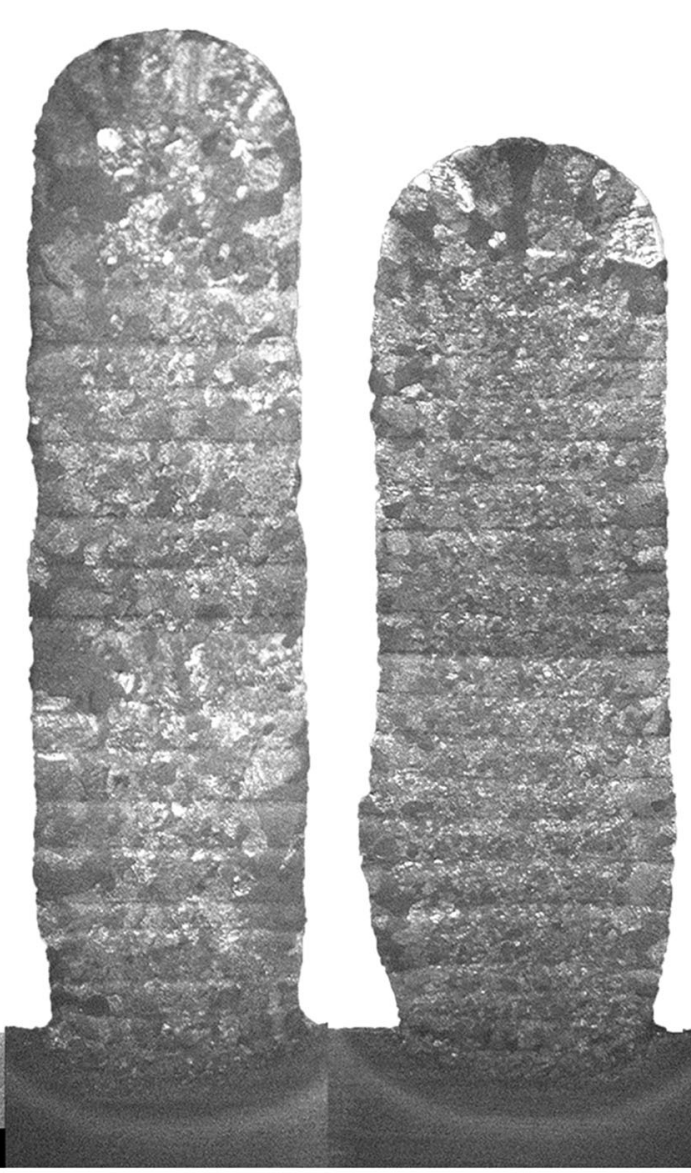

(b)

(c)

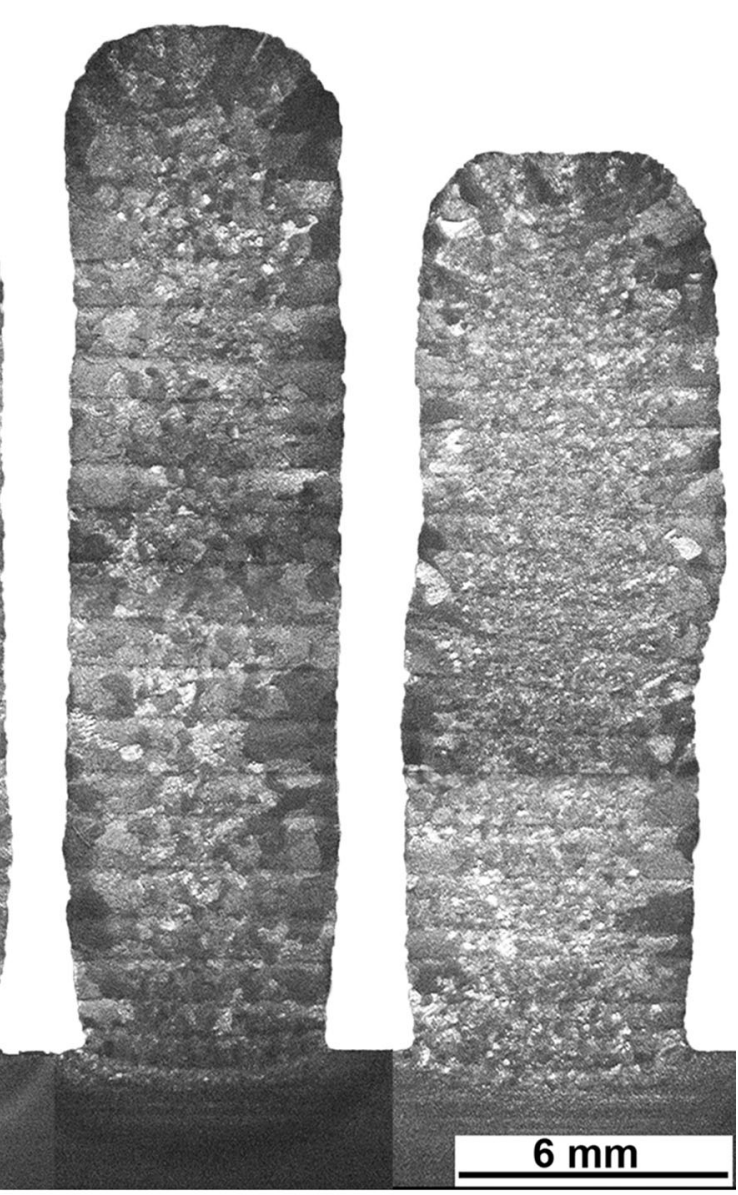

(d)

(e)

Fig. 3 - Optical microscopy images of cross sections taken from $Y Z$ plane from $(a)$ control sample, (b) sample rolled at $50 \mathrm{kN}$, and $(c)$ sample rolled at $75 \mathrm{kN}$ with the profiled roller; and $(d)$ sample rolled at $50 \mathrm{kN}$ and $(e)$ sample rolled at $75 \mathrm{kN}$ with the flat roller. Note the difference in the components' height and width. 
changes, occurring as a result of rolling and deposition. Baseplates were $250-\mathrm{mm}$ long, $60-\mathrm{mm}$ wide, and 6- $\mathrm{mm}$ thick, and were clamped by screws along each side of the plate. In this study, four linear walls of 20 layers each were deposited without any interpass rolling. Subsequently, the following treatments were applied: for two walls, only the last layer was rolled with loads of 50 and $75 \mathrm{kN}$, respectively; for the other two, only the last layer was rolled at 50 and $75 \mathrm{kN}$, respectively, after which an additional layer was deposited. Only the profiled roller was used for this investigation. These four walls were sectioned, and critical points in terms of microstructural changes were identified. The sample rolled at $75 \mathrm{kN}$ with a subsequent layer deposited was repeated: before depositing the 21st layer, two R-type thermocouples were spot welded into the bottom of $\phi 3.2 \times 3 \mathrm{~mm}$ deep holes, 4.5 and $4.9 \mathrm{~mm}$ below the top. These holes corresponded to 5.6 and $6 \mathrm{~mm}$ below the expected top of the 21 st layer. Finally, the same experiment was repeated a further two times to validate the temperature measurements $6 \mathrm{~mm}$ below the surface; one measured the temperature at four points with R-type thermocouples, and one measured it at four more points with K-type thermocouples.

\section{RESULTS}

\section{A. Strain}

Average engineering strains are shown in Table III. The strains for the two directions were very similar for the samples rolled with the profiled roller; however, the strain was greater in the transverse direction $\left(\epsilon_{y}\right)$ for the sample rolled with the flat roller.

\section{B. Microstructure}

The cross-sectional microstructures from the five samples are shown in Figure 3. All the samples were slightly narrower near the baseplate due to the different heat flow in this region. ${ }^{[2]}$

The control sample demonstrates large, columnar prior $\beta$ grains, which grew epitaxially from the baseplate toward the top of the sample (Figures 3(a) and 4). The thickness of these grains ranged from 1 to $3 \mathrm{~mm}$ and could traverse the whole height of the deposit.

In the rolled samples, there was a significant reduction in the prior $\beta$ grain size which decreased with increasing rolling load. High-magnification optical microscopy images taken from the three main sectioning planes $(Y Z, X Z$ and $X Y$ ) are shown in Figures 5 through 7. Prior $\beta$ grain size was measured using images from the $Y Z$ cross-sectional plane and is reported in Table IV.

Horizontal bands were observed in the macrostructures of all the samples, one being produced with each deposited layer (Figures 3 and 8(a)). In addition, columnar prior $\beta$ grains were observed in the top ca. $2 \mathrm{~mm}$ of all samples. Furthermore, in the top layers of all samples, martensite was found, which is evidenced by a characteristic needle-like microstructure ${ }^{[18]}$ and is shown in Figure 8(b) for the sample rolled at $75 \mathrm{kN}$ with the profiled roller.
The rest of the sample had a Widmanstätten microstructure (Figure 8(c)). SEM images taken from the $Y Z$ sectioning plane at locations A, B, C, D, E (see Figure 8(a)) are shown in Figures 9 through 11, for the control and specimens rolled at 50 and $75 \mathrm{kN}$, respectively. The thickness of the $\alpha$ phase lamellae, measured from these images, is plotted in Figure 8(d).

There are two differences that need to be considered: the difference due to the location within the band; and the difference due to the rolling load. With respect to the first, the variation is obvious being well outside the confidence interval of the mean indicated in Figure 8(d), and the thickness of the $\alpha$ lamellae was larger near the top of the band (point E) and smaller near the bottom of the band (point A). With respect to the second, the difference is less, particularly for locations $\mathrm{C}, \mathrm{D}$, and $\mathrm{E}$. To assess this, the $p$ values comparing the statistical significance of the different rolling loads are provided in Table $\mathrm{V}$.

The main difference between the microstructures produced by the flat and profiled rollers is the size of the prior $\beta$ grains along the sides of the samples. While the grain size was fairly uniform across the sample with the profiled roller (Figures 3(b) and (c)), the sample produced with the flat roller had grains that were approximately five to ten times bigger along the sides

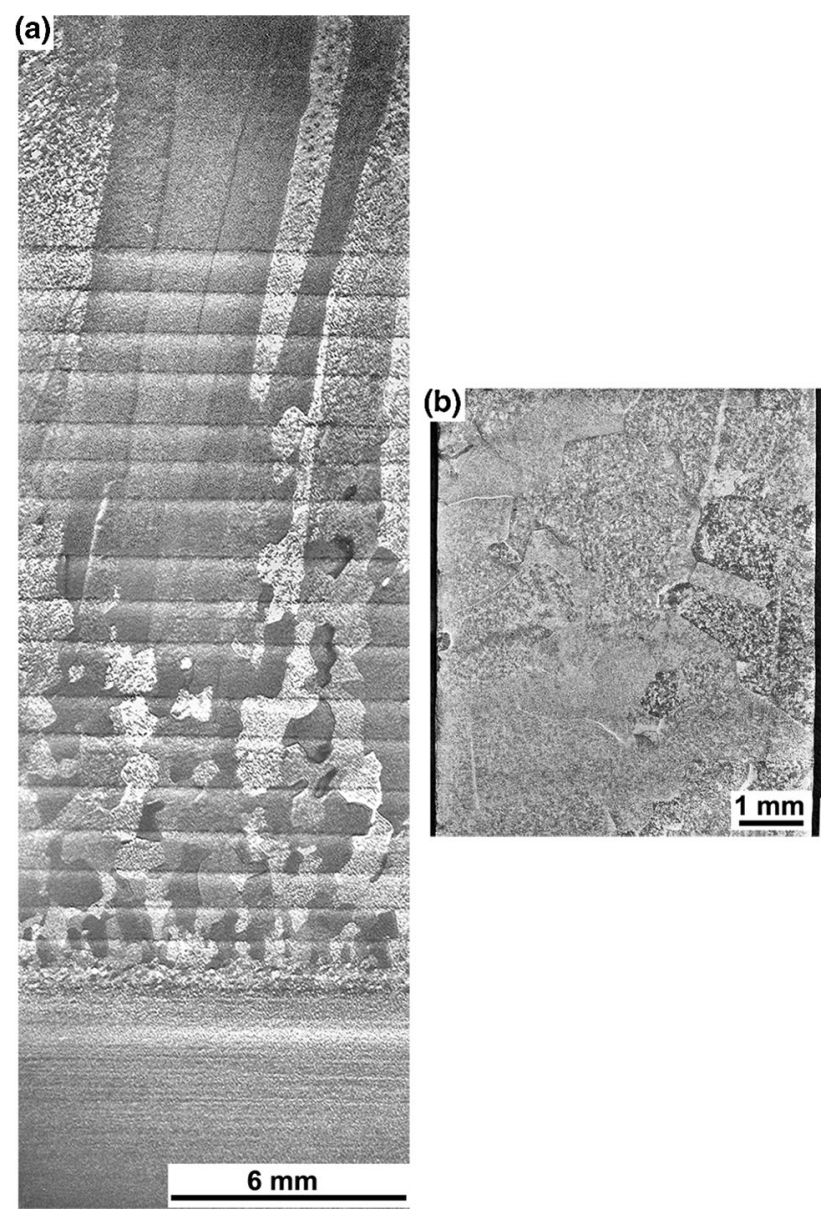

Fig. 4 - Optical microscopy images of control sample cross sections taken from (a) $X Z$ and (b) $X Y$ sectioning planes. 

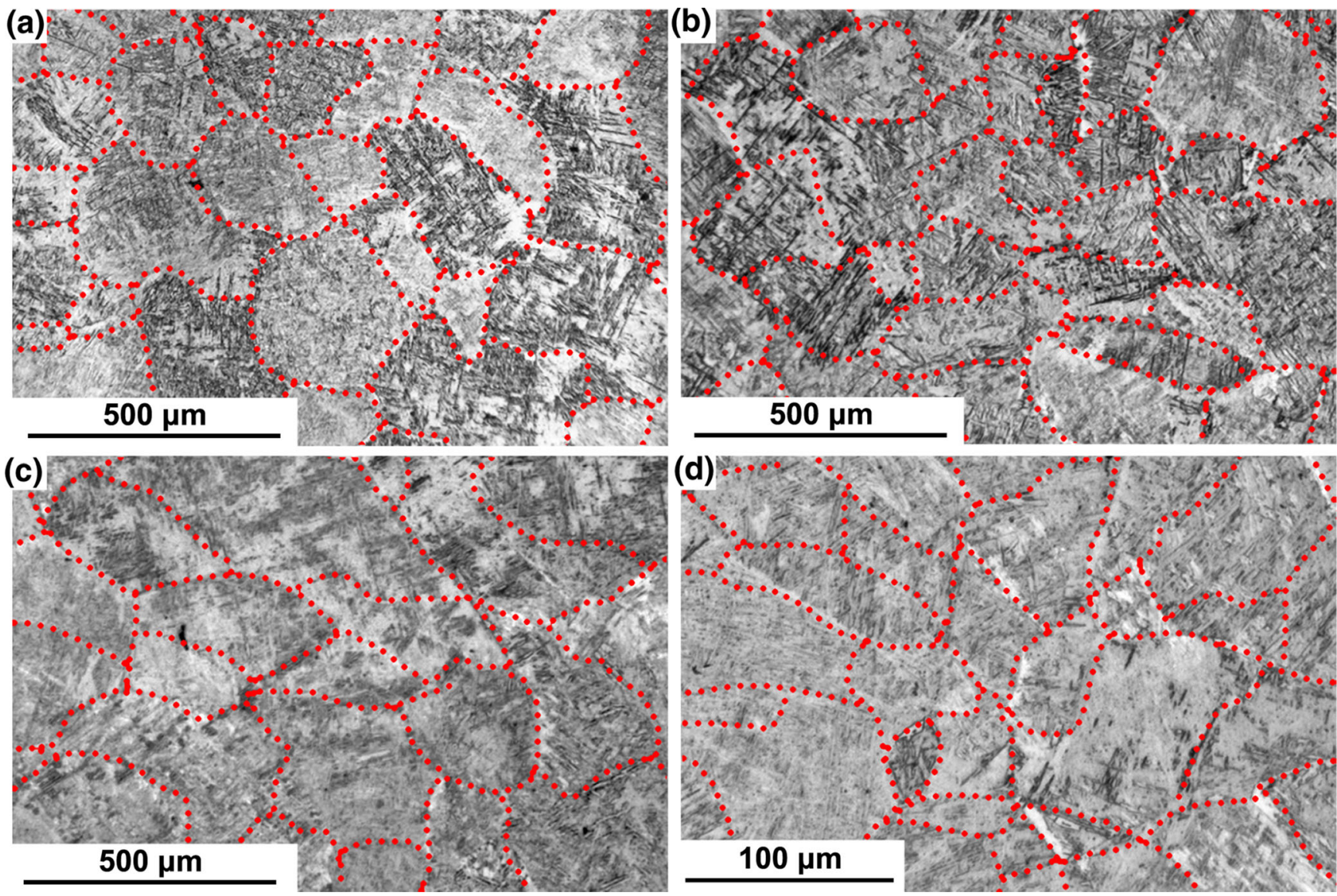

Fig. 5-High-magnification optical microscopy images of cross sections taken on the $Y Z$ sectioning plane from $(a)$ profiled roller, $50 \mathrm{kN}$; $(b)$ profiled roller, $75 \mathrm{kN} ;(c)$ flat roller, $50 \mathrm{kN}$; and $(d)$ flat roller, $75 \mathrm{kN}$. Prior $\beta$ grain boundaries are highlighted for reader's convenience.

(Figures 3(d) and (e)). This is highlighted in high-magnification optical microscopy images taken from the edges of the samples, from the $X Y$ sectioning plane and collected in Figure 12.

The microstructures of the samples from the fundamental study are shown in Figure 13. Figures 13(b) and (d) show the samples whose last layer was rolled only; due to process noise, it is impossible to determine exactly the extent of the plastic deformation induced by the rolling step. However, it is possible to identify the shift in the $Z$ coordinates of the top band (highlighted by the red lines), as well as a modest reduction in height. Apart from the deformation induced by the roller, the appearance of these samples was relatively unchanged.

The samples that had a subsequent layer deposited (Figures 13(a) and (e), high-magnification optical microscopy images shown in Figure 14) had a significantly different microstructure. There were three different regions which are labeled with (1), (2), and (3) in Figure 14. (1), closer to the top of the deposit, exhibited columnar prior $\beta$ grains aligned with the $Z$ axis. These grains grew from grains within the region (2), located below, which was characterized by a refined equiaxed microstructure. Region (3) had long columnar prior $\beta$ grains that were identical to those observed in the control. The microstructure of the $\alpha$ phase within these regions was also significantly different. Within regions (1) and (2), the microstructure was predominantly martensitic, while in region (3), the microstructure was the Widmanstätten microstructure that is observed in the bulk material. The boundary between regions (2) and (3), namely the recrystallization boundary, was located 4.8 and $5.6 \mathrm{~mm}$ from the top surface, respectively, for the 50 and $75 \mathrm{kN}$ specimens with a subsequent deposited layer (Figures 14(a) and (b)). For the latter, the peak temperatures at the recrystallization boundary and at the first horizontal band in the deposited microstructure are shown in Figure 15. The recrystallization boundary had a peak temperature of $1053 \mathrm{~K}$ $\left(780{ }^{\circ} \mathrm{C}\right.$ ) and a cooling rate from $973 \mathrm{~K}$ to $673 \mathrm{~K}$ $\left(700{ }^{\circ} \mathrm{C}\right.$ to $400{ }^{\circ} \mathrm{C}$ ) of $8.4 \mathrm{~K} / \mathrm{s}$; the first band, after removing the three outliers at $862 \mathrm{~K}, 1263 \mathrm{~K}$, and $1341 \mathrm{~K}\left(589{ }^{\circ} \mathrm{C}, 990{ }^{\circ} \mathrm{C}\right.$, and $\left.1068{ }^{\circ} \mathrm{C}\right)$ had a peak temperature of $1013 \mathrm{~K}\left(740{ }^{\circ} \mathrm{C}\right)$ and a similar cooling rate from $973 \mathrm{~K}$ to $673 \mathrm{~K}\left(700{ }^{\circ} \mathrm{C}\right.$ to $\left.400{ }^{\circ} \mathrm{C}\right)$ of $7.4 \mathrm{~K} / \mathrm{s}$. In Figure 15, the temperature distribution of the first band was based on six-point averages calculated every five seconds. Error bars were calculated in the same way.

\section{DISCUSSION}

\section{A. Prior $\beta$ Grains}

The grain refinement that is achieved with the combination of rolling and deposition is a key finding. 

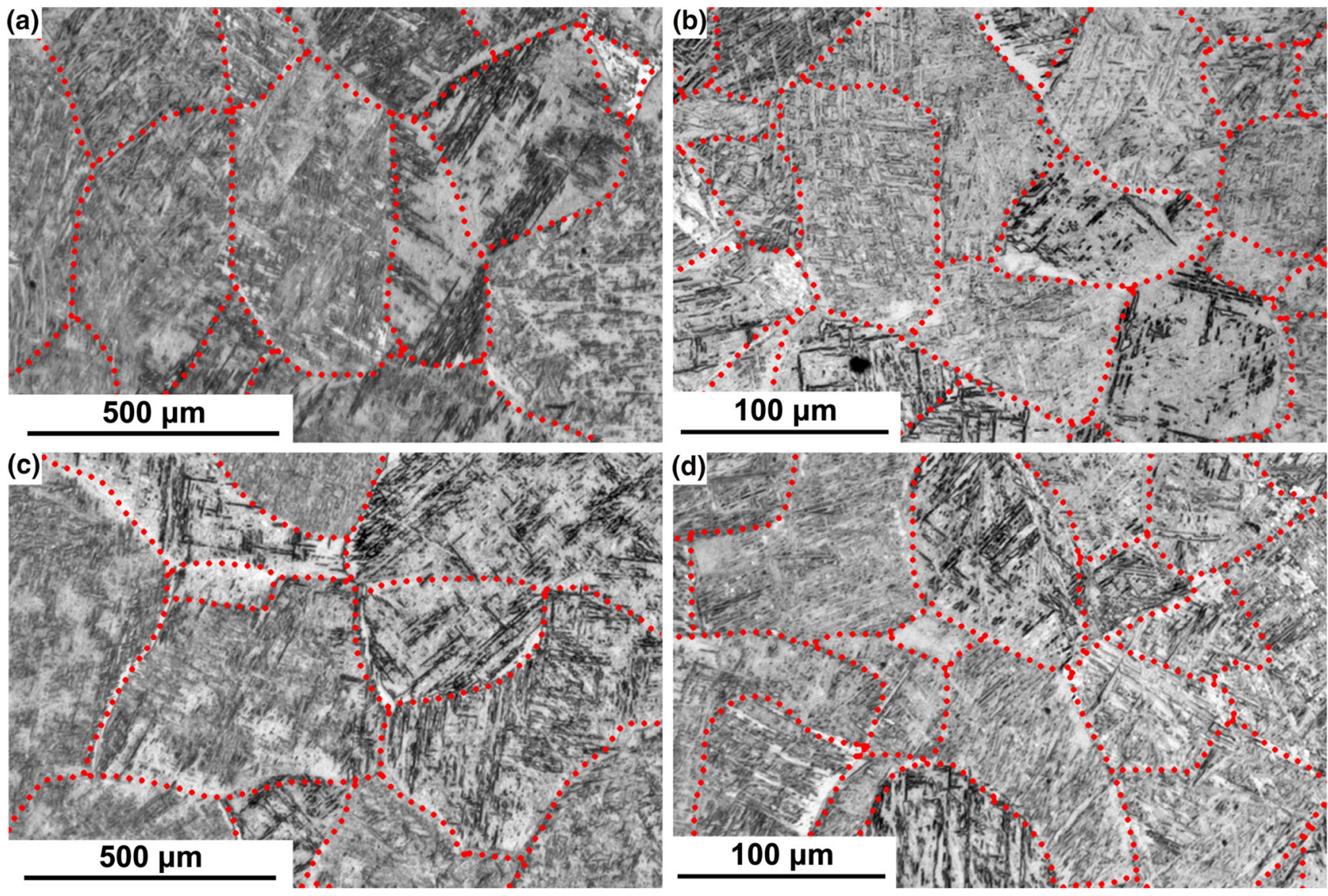

Fig. 6-High-magnification optical microscopy images of cross sections taken on the $X Z$ sectioning plane from $(a)$ profiled roller, $50 \mathrm{kN}$; $(b)$ profiled roller, $75 \mathrm{kN} ;(c)$ flat roller, $50 \mathrm{kN}$; and $(d)$ flat roller, $75 \mathrm{kN}$. Prior $\beta$ grain boundaries are highlighted for reader's convenience.

Understanding the mechanism that causes this is complex: the final microstructure is a consequence of the combination of deformation from rolling and the subsequent heat treatment from the deposition process. To the authors' knowledge, this kind of microstructural change in titanium (static recrystallization) has not been reported elsewhere.

Investigations of static recrystallization on titanium are mostly limited to commercially pure titanium where the kinetics of the transformation are not complicated by the presence of a second phase. This is an example of "classic" recrystallization where rolling introduces stacking faults, points defects, dislocations, and twins which provide the driving force for recrystallization when the material is heated above the recrystallization temperature. The recrystallization temperature in commercially pure titanium is $921 \mathrm{~K}$ to $942 \mathrm{~K}\left(646{ }^{\circ} \mathrm{C}\right.$ to $\left.669^{\circ} \mathrm{C}\right)$, well below the $\beta$ transus temperature of $1155 \mathrm{~K}\left(882{ }^{\circ} \mathrm{C}\right) .^{[19]}$ There is a single investigation on static recrystallization of Ti-6Al-4V which investigates recrystallization up to temperatures of $1153 \mathrm{~K}\left(880{ }^{\circ} \mathrm{C}\right) .{ }^{[20]}$ There is considerably more work on dynamic recrystallization of Ti-6Al-4V which occurs during hot deformation. In Seshacharyulu et al. ${ }^{[21]}$ recrystallization of the $\beta$ phase was observed at $1373 \mathrm{~K}\left(1100{ }^{\circ} \mathrm{C}\right)$ and relatively low strain-rates of $0.01 \mathrm{~s}^{-1}$.
In the fundamental study, the temperature at the recrystallization boundary $(5.6 \mathrm{~mm}$ from the top, see Figure 15) was $1053 \mathrm{~K}\left(780{ }^{\circ} \mathrm{C}\right)$, below the $\beta$-transus temperature and the $\beta$ phase recrystallization temperature mentioned in Seshacharyulu et al. ${ }^{[21]}$ Since errors in this measurement can occur due to precise placement of the thermocouple which is exacerbated by the steep thermal gradient, the measurement was repeated nine times to improve confidence in this finding. The significant influence of the rolling load on the position of the recrystallization boundary (see Figures 14(a) vs (b)) suggests that it is dependent on the amount of strain rather than the peak temperature. Although they modeled rolling of friction stir welds, Colegrove et al. ${ }^{[22]}$ showed that the higher the rolling load, the deeper the deformation, which appears to strongly influence the recrystallization of the material.

A higher rolling load also introduced more stored energy. This explains why for the same deposition parameters (which corresponded to identical heat treatment conditions) the $75 \mathrm{kN}$ specimens underwent more recrystallization, and exhibited smaller prior $\beta$ grains.

Finally, the results with the flat roller demonstrated a non-uniform refinement of the prior $\beta$ grain size, which is larger along the side of the walls. As seen in Figures 3(d) and (e), the flat roller causes a significant amount of flattening of the deposited material. 

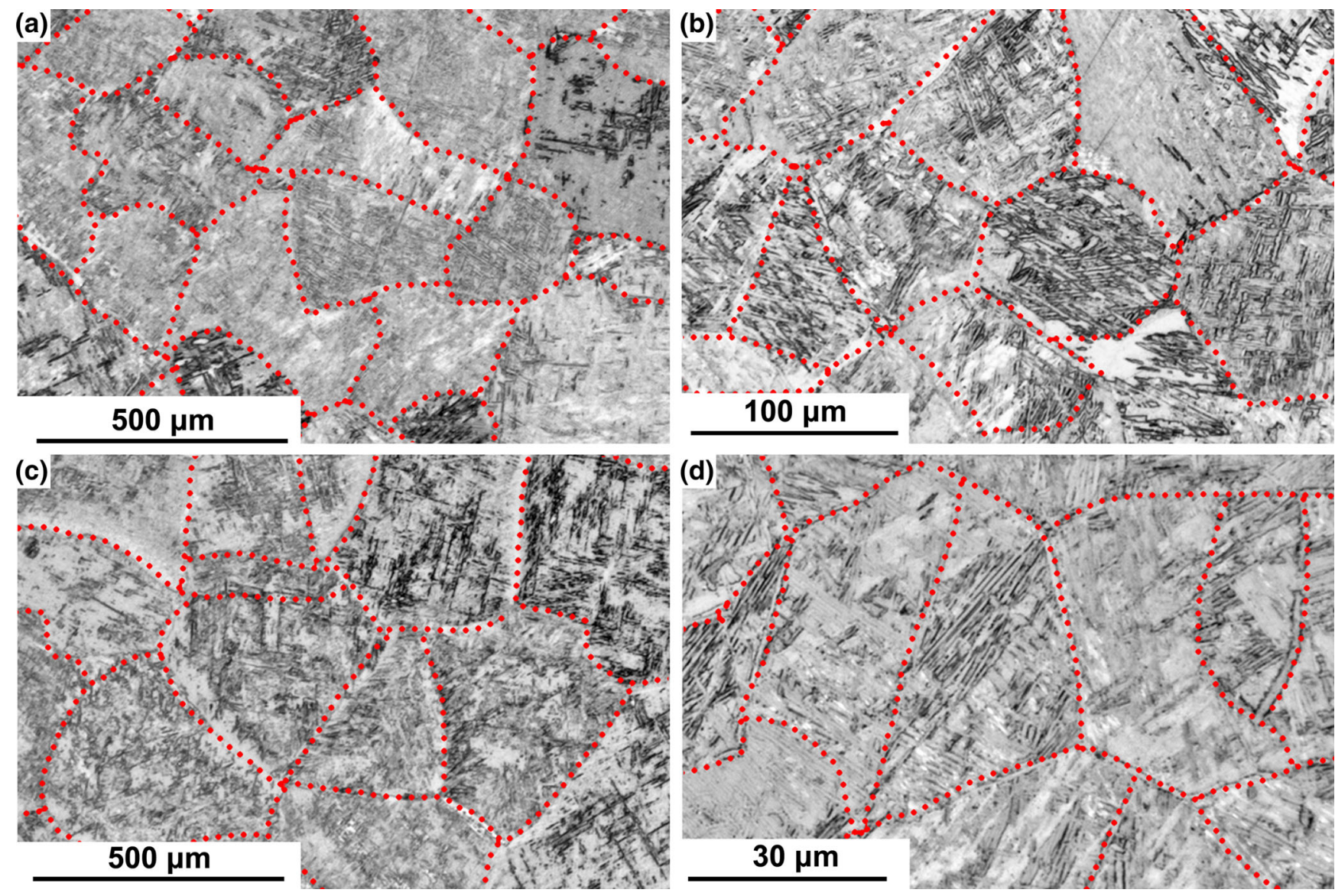

Fig. 7-High-magnification optical microscopy images of cross sections taken on the $X Y$ sectioning plane from $(a)$ profiled roller, $50 \mathrm{kN}$; $(b)$ profiled roller, $75 \mathrm{kN}$; $(c)$ flat roller, $50 \mathrm{kN}$; and $(d)$ flat roller, $75 \mathrm{kN}$. Prior $\beta$ grain boundaries are highlighted for reader's convenience.

Table IV. Prior $\beta$ Grain Sizes

\begin{tabular}{lcccr}
\hline & \multicolumn{2}{c}{$50 \mathrm{kN}$} & \multicolumn{2}{c}{$75 \mathrm{kN}$} \\
\cline { 2 - 3 } & Average $(\mu \mathrm{m})$ & SD & & Average $(\mu \mathrm{m})$ \\
\hline Profiled roller & 125 & 29.5 & 89 & SD \\
Flat roller & 139 & 20.8 & 56 & 6.2 \\
\hline
\end{tabular}

Therefore, the strain induced in the material is likely to be concentrated around the center of the deposit. Since there is a link between the strain in the material and the subsequent prior $\beta$ grain size, which is evidenced by the correlation between the rolling load and prior $\beta$ grain size in Table IV, the concentration of strain in the center of the deposit causes the greater grain refinement in this region.

\section{B. $\alpha$ Phase and Banding}

The temperature of the point that is associated with the top band in the microstructure $(6 \mathrm{~mm}$ from the top surface) was $1013 \mathrm{~K}\left(740^{\circ} \mathrm{C}\right)$. Within the limits of experimental error, this point appears to be related more to the $\alpha$ dissolution temperature of $1021 \mathrm{~K}\left(748^{\circ} \mathrm{C}\right),{ }^{[23]}$ than to the $\beta$-transus temperature as previously suggested. $^{[2]}$ Please note the precise value for these transition temperatures can vary according to heating rates and conditions. ${ }^{[24]}$

The gradient in the $\alpha$ lamellae size shown in Figure $8(d)$, already observed in plasma ${ }^{[2]}$ and $\operatorname{laser}^{[23,25]}$ deposited Ti-6Al-4V structures, is due to the differences in peak temperatures and cooling rates observed in different $Z$ coordinates during the deposition of a layer. This concept was presented in Martina et al. ${ }^{[2]}$ and will be refined further here. As shown in Figure 8(e), a typical thermal cycle may be simplified into three main sections: heating (stage 1 ), a period $t_{\mathrm{P}}$ when the material is around the peak temperature $T_{\mathrm{P}}$ (stage 2 ), and cooling (stage 3). It was suggested there is little difference in cooling rate in the top 4 to $6 \mathrm{~mm}$ of the deposited structure, i.e., irrespective of the peak temperature and distance from the heat source, the average cooling rate on the tail (stage 3 ) is similar. ${ }^{[2]}$ This is confirmed by the experimental measurements shown in Figure 15, where 


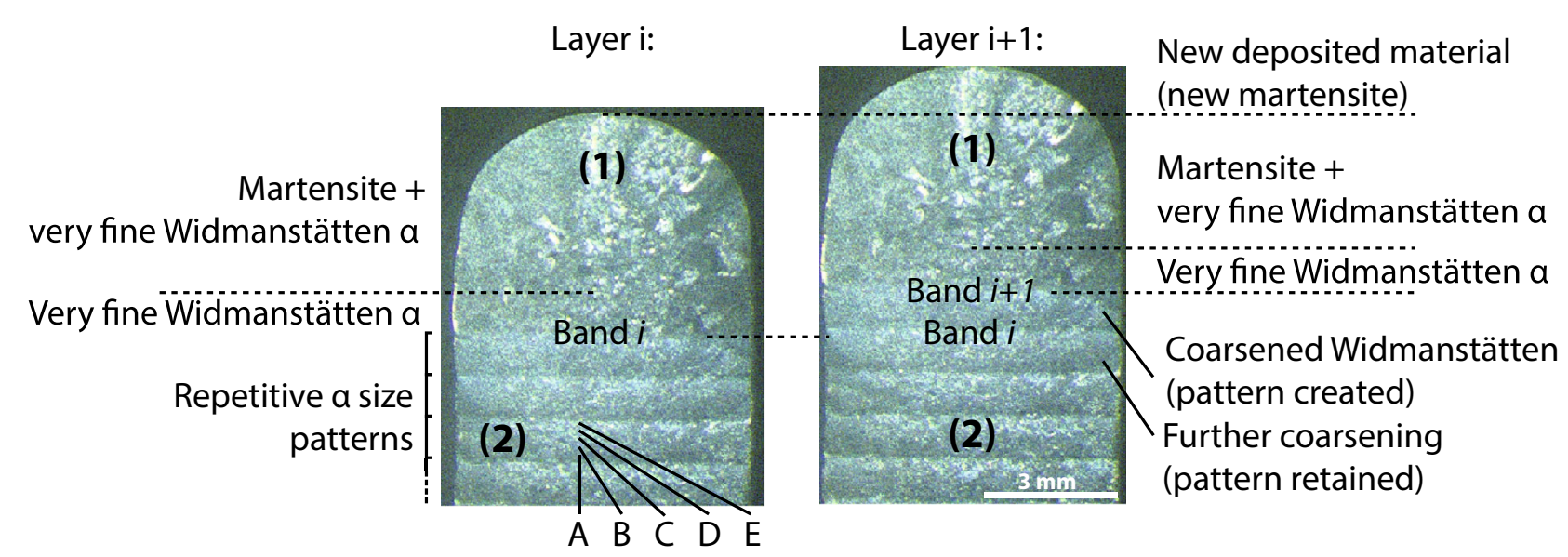

(a)

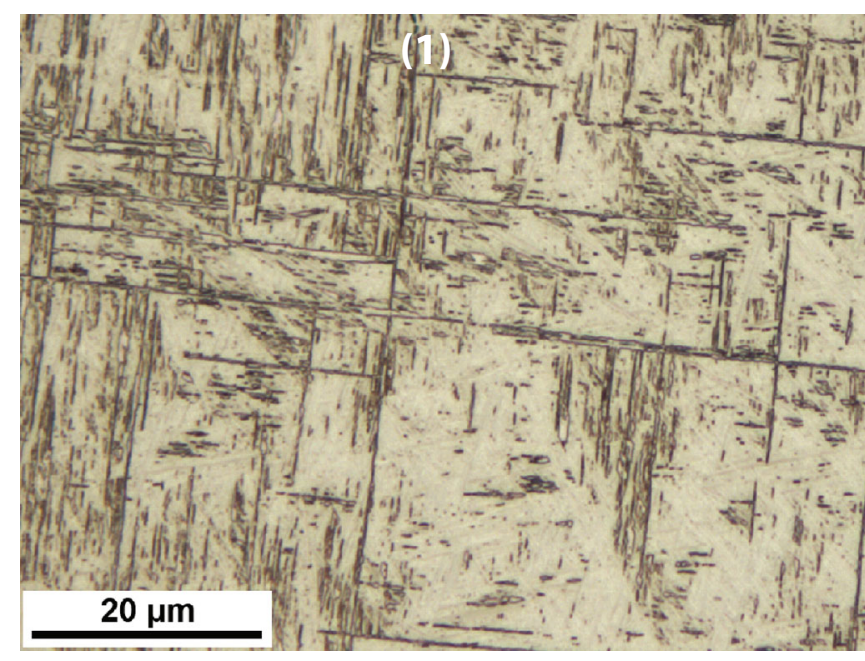

(b)

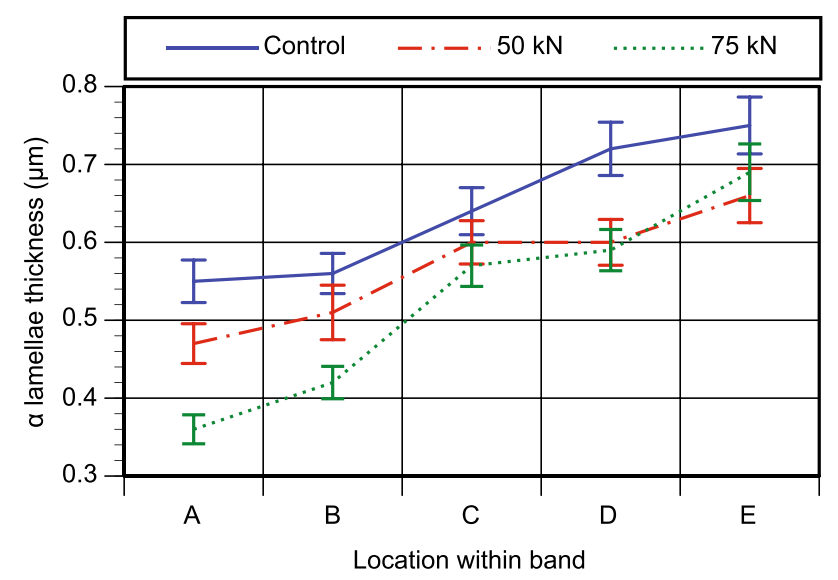

(d)

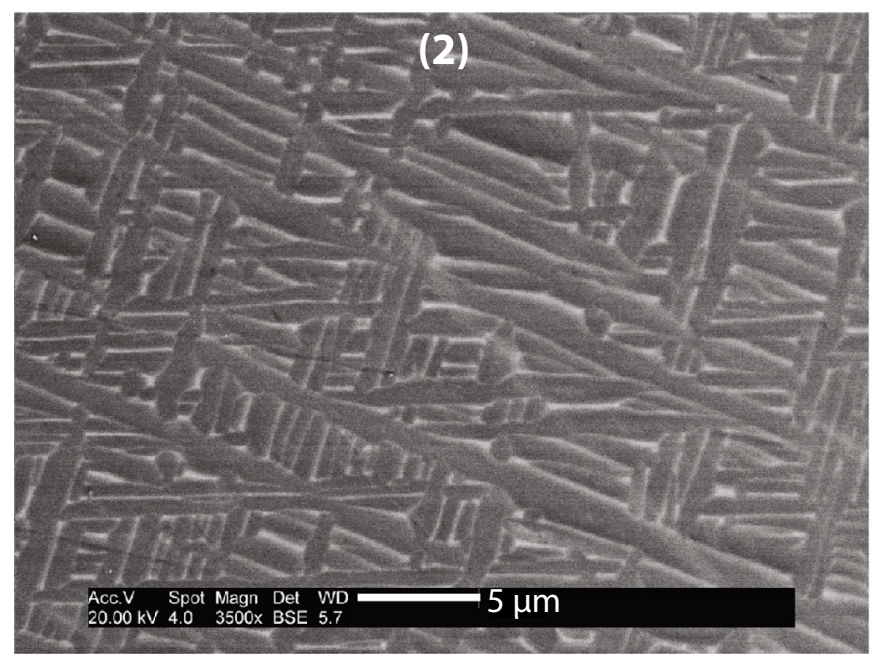

(c)

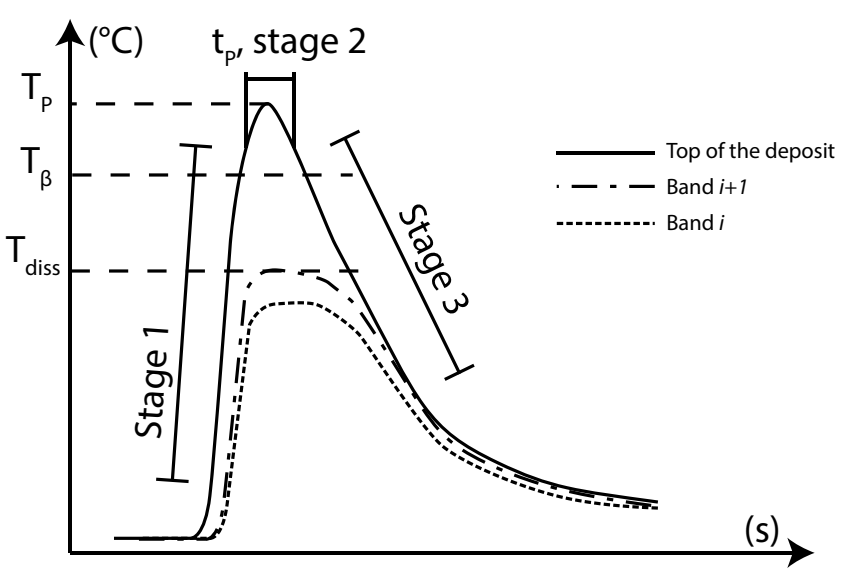

(e)

Fig. 8- (a) Microstructure observed before and after the deposition of a new layer, and their locations within the components; $(b)$ optical microscopy image of martensite observed in the top of the sample rolled at $75 \mathrm{kN} ;(c)$ scanning electron microscope (SEM) image of the Widmanstätten microstructure observed in the rest of the samples; (d) plot of the $\alpha$ thickness $v s$ the locations showed in (a) (error bars indicate 95 pct confidence interval of the mean); (e) cooling curves for top of deposit, first band, and area immediately below. 


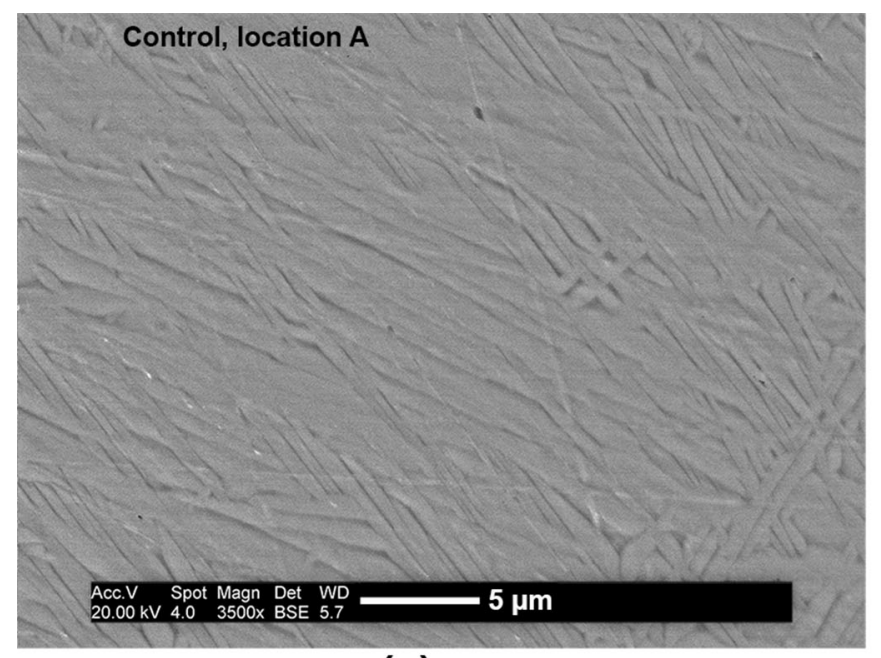

(a)

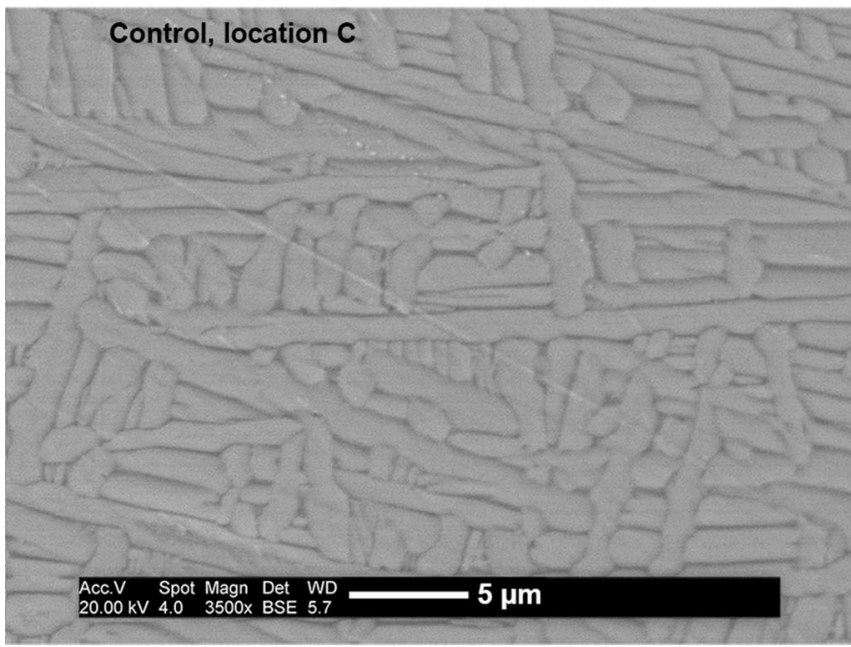

(c)

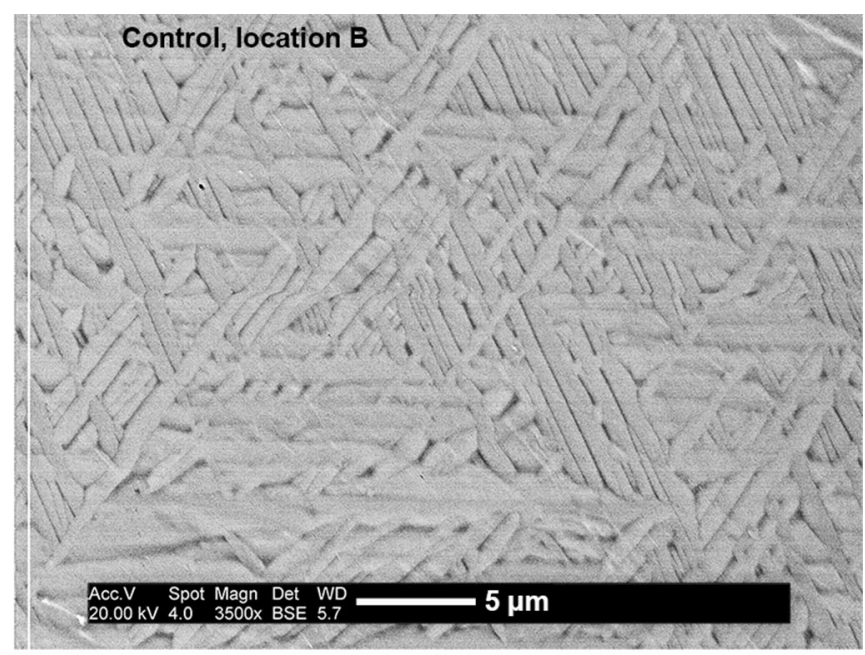

(b)

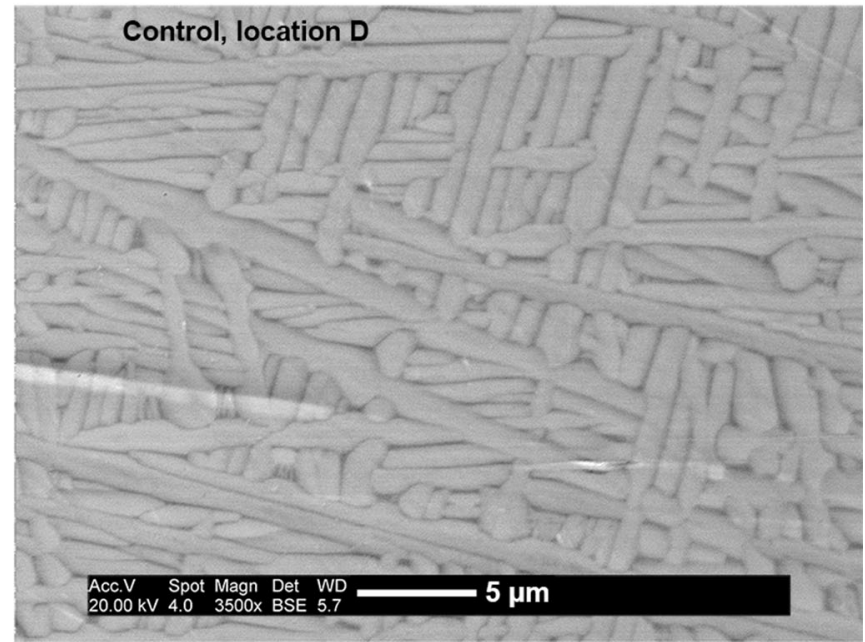

(d)

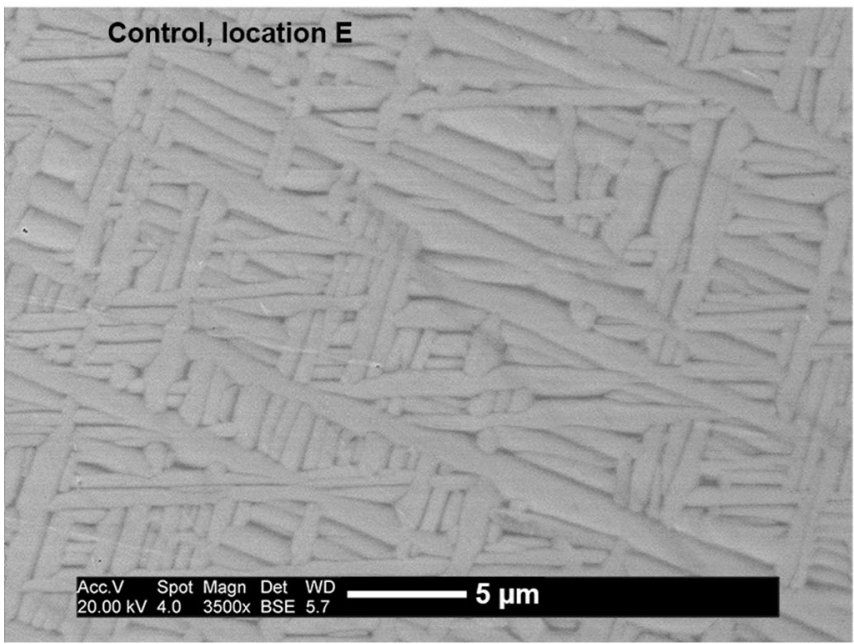

(e)

Fig. 9-Scanning electron microscope (SEM) images taken from the control sample to show the increase in the thickness of the $\alpha$ phase. $(a)$ Taken from Location A; $(b)$ taken from Location B, $(c)$ taken from Location C, $(d)$ taken from Location D, and $(e)$ taken from Location E. The locations of $\mathrm{A}$ to $\mathrm{E}$ within each band are shown in Fig. 8(a). 


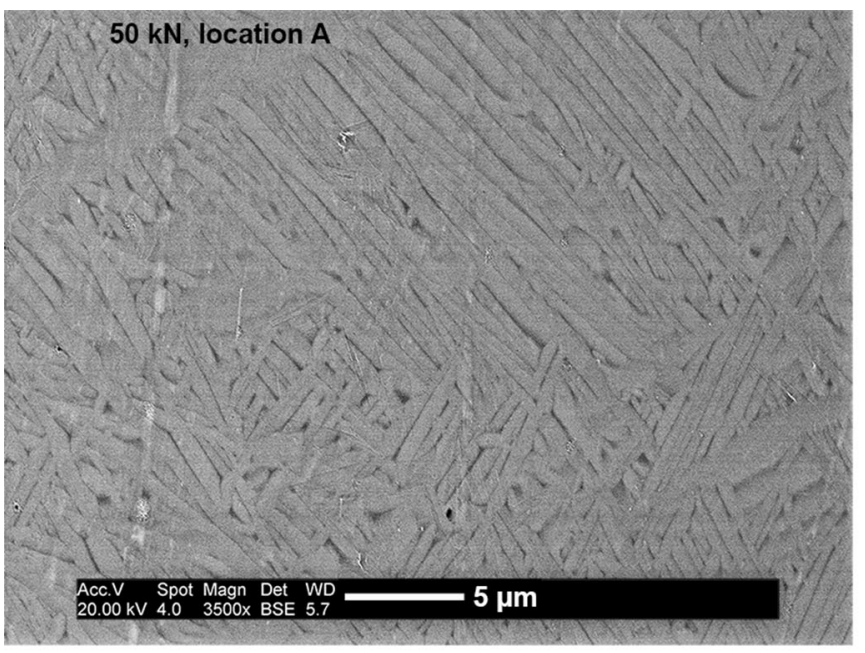

(a)

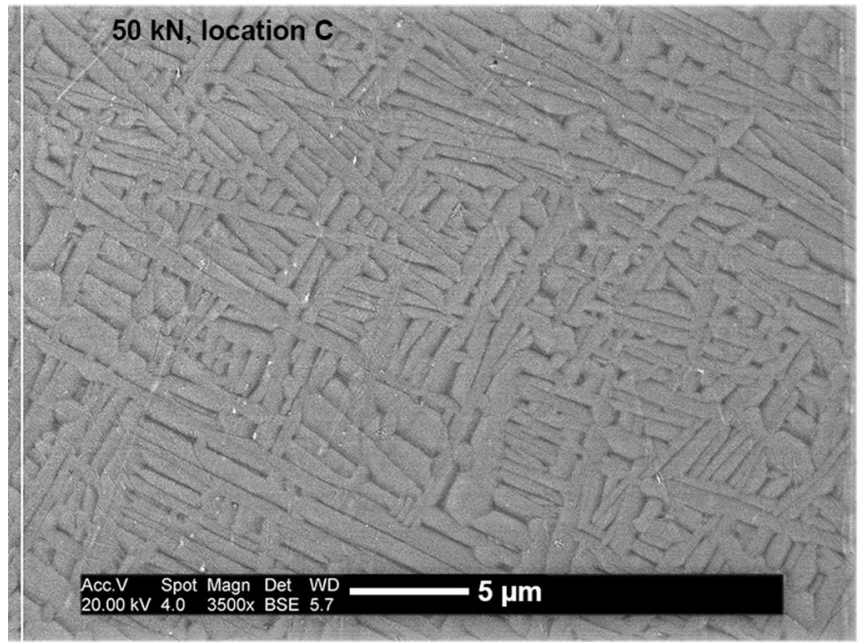

(c)

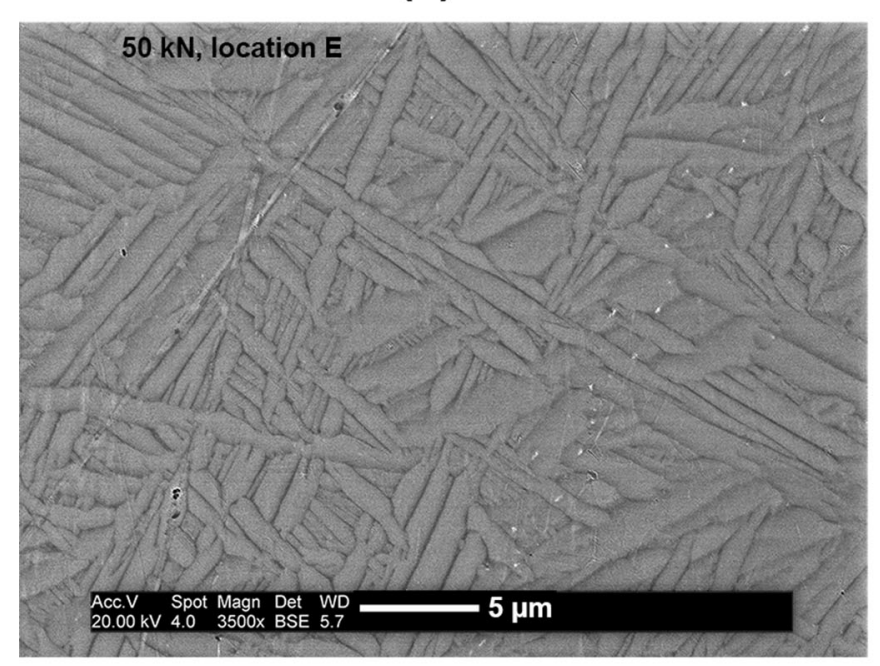

(e)

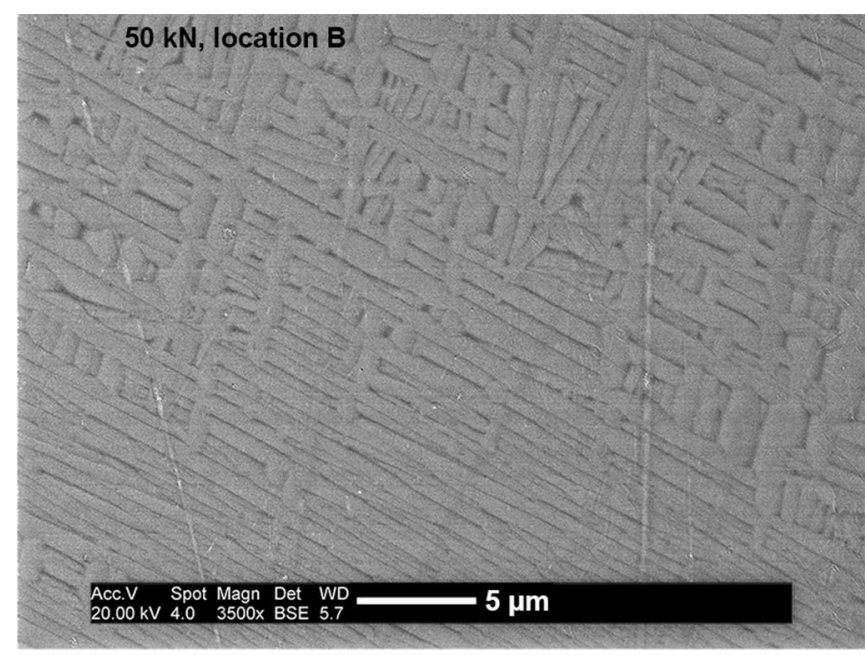

(b)

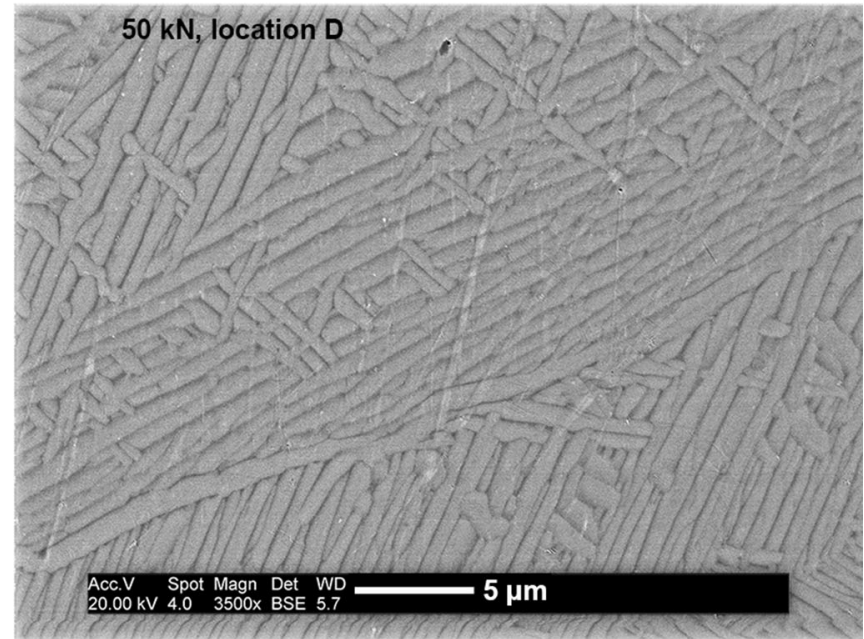

(d)

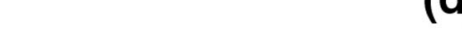




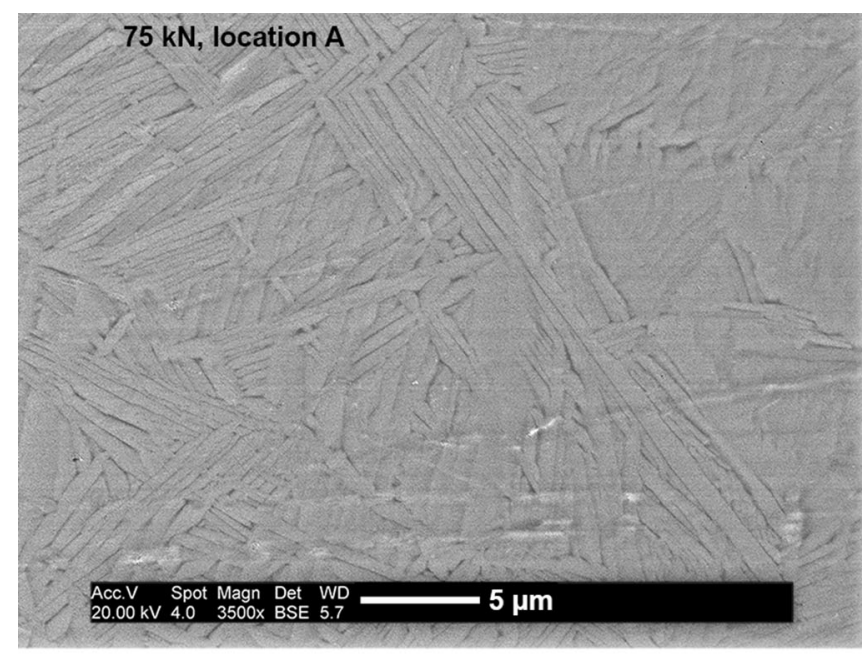

(a)

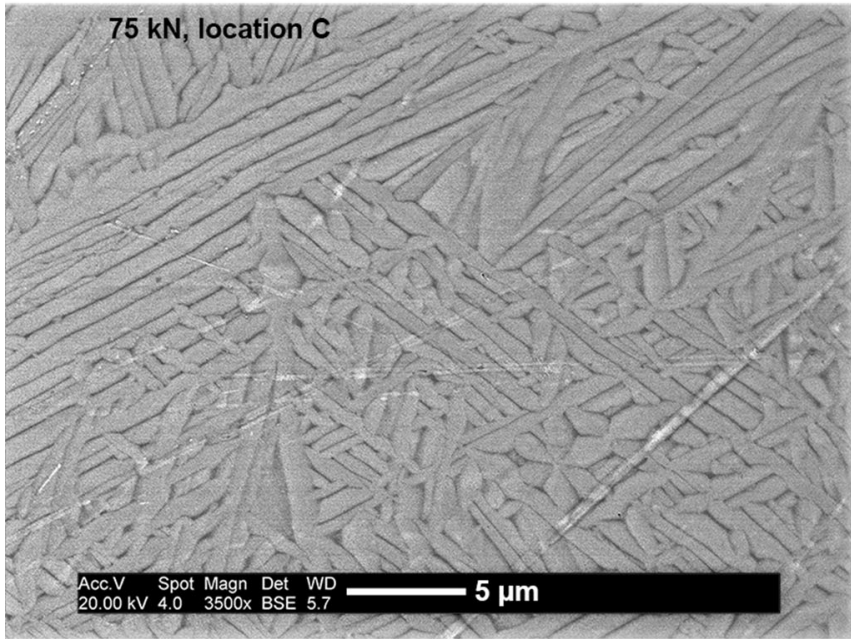

(c)

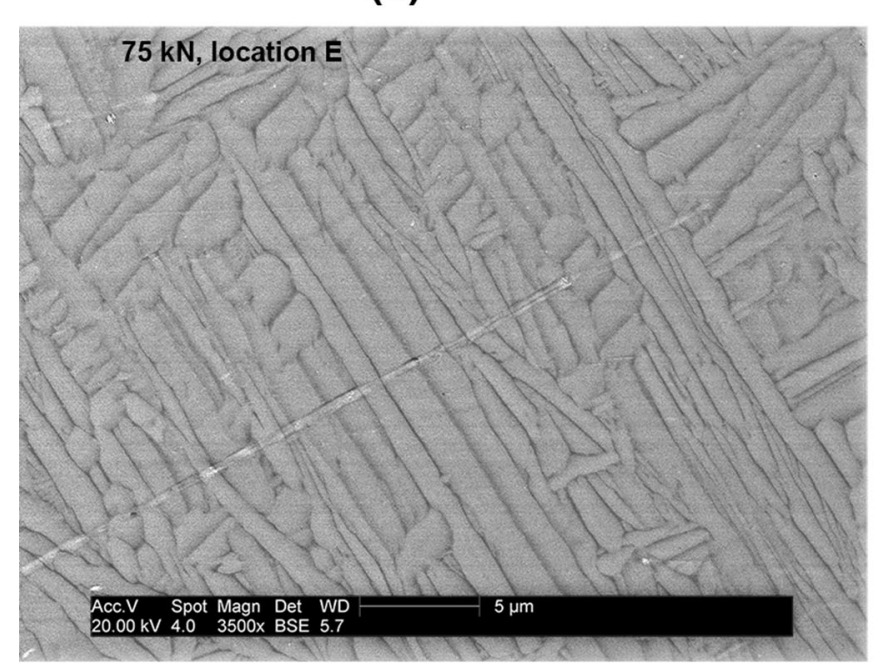

(e)

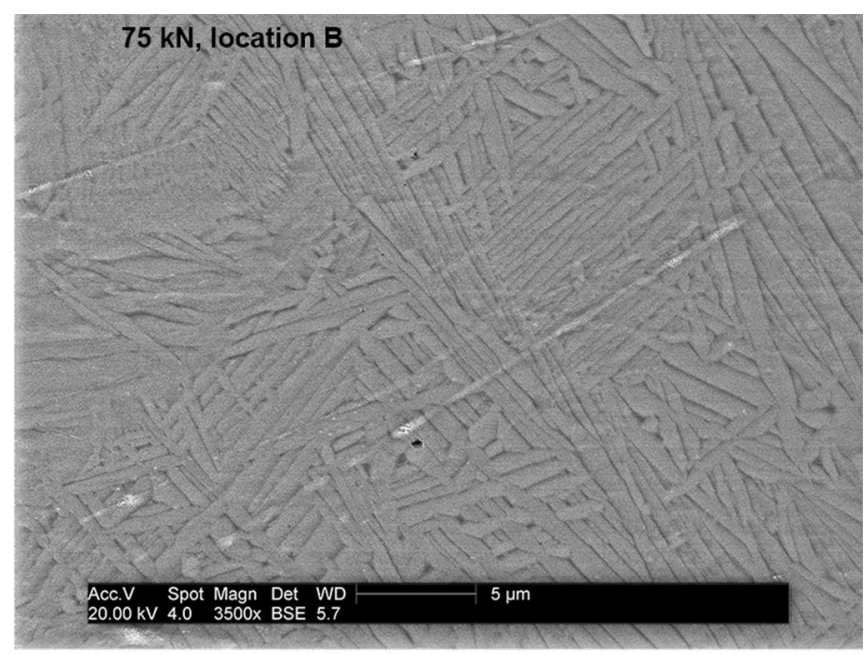

(b)

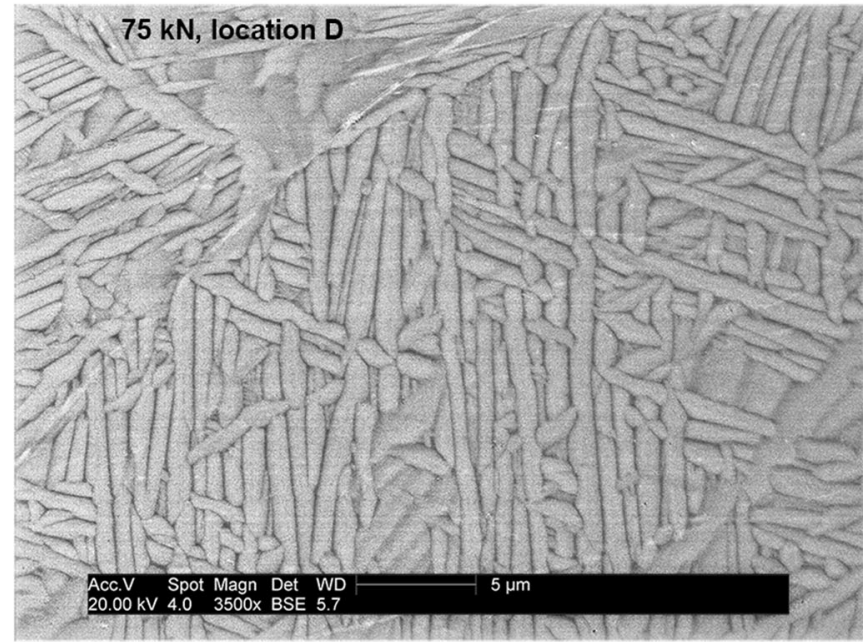

(d)

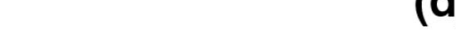


Table V. $\quad P$ Values of Student's $T$ Tests Performed on the Size Distribution of the Measured $\alpha$ Lamellae Thickness of a Specific Location Against the Same Corresponding to Another Sample

\begin{tabular}{lccccc}
\hline & A & B & C & D & E \\
\hline Control vs 50 kN & $<0.001$ & $<0.05$ & $<0.05$ & $<0.001$ & $<0.001$ \\
Control vs 75 kN & $<0.001$ & $<0.001$ & $<0.001$ & $<0.001$ & $<0.05$ \\
$50 \mathrm{kN}$ vs 75 kN & $<0.001$ & $<0.001$ & 0.14 & 0.74 & 0.14 \\
\hline
\end{tabular}
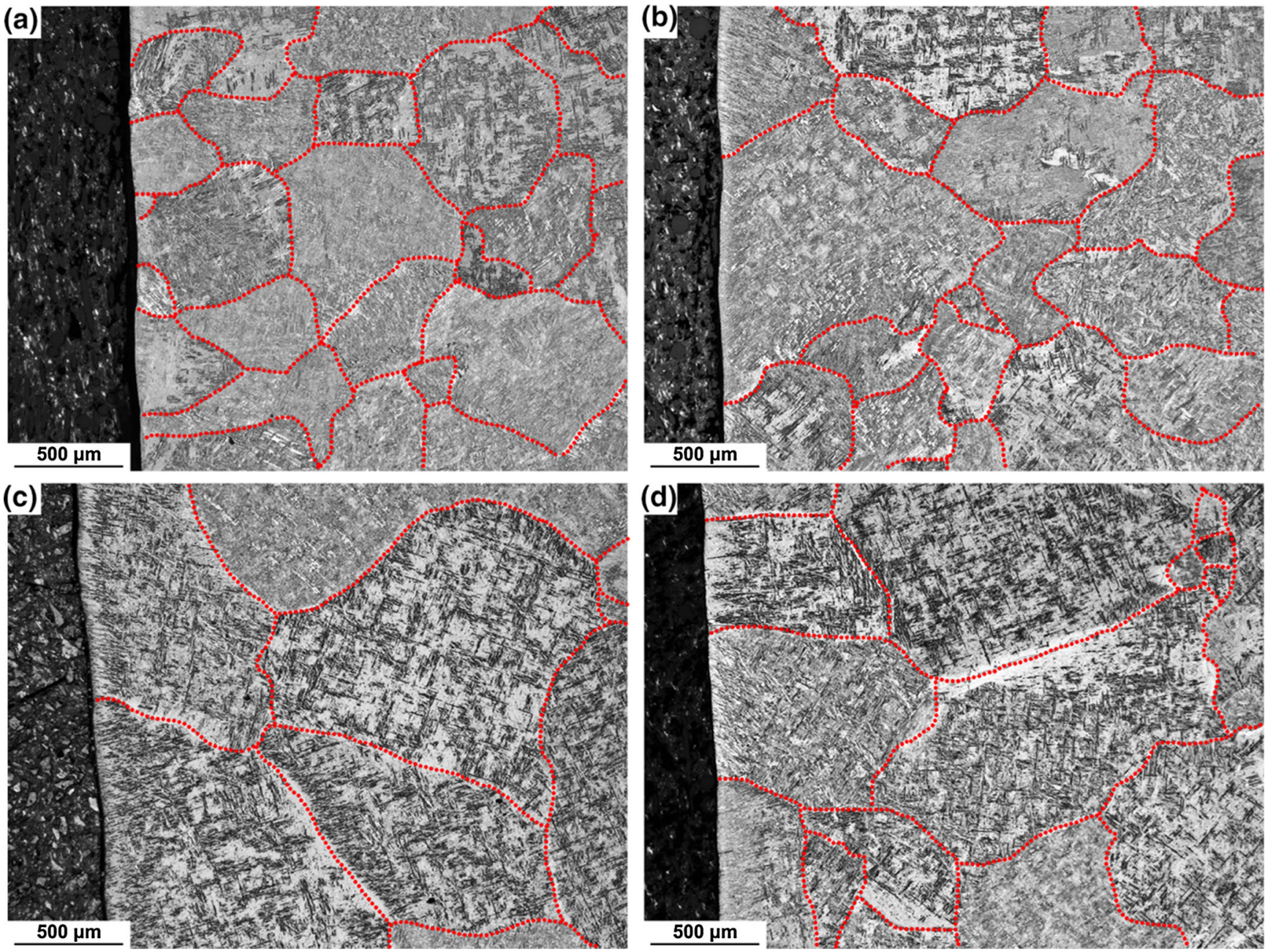

Fig. 12-High-magnification optical microscopy images of cross sections taken on the $X Y$ plane from $(a)$ profiled roller, $50 \mathrm{kN} ;(b)$ profiled roller, $75 \mathrm{kN} ;(c)$ flat roller, $50 \mathrm{kN}$; and $(d)$ flat roller, $75 \mathrm{kN}$. These images are taken on the edge of the samples to highlight the different grain size produced by the two types of rollers for the same load. Prior $\beta$ grain boundaries are highlighted for reader's convenience.

the cooling rate at the two locations $(7.4$ to $8.4 \mathrm{~K} / \mathrm{s})$ was sufficient to produce at least a partially martensitic microstructure. ${ }^{[26]}$

Upon deposition of a new layer $i+1$ which creates the band $i+1$ (see Figure 8(a)), martensite is produced in the newly deposited material. Immediately below, the material deposited during layer $i$ is taken above the $\beta$ transus temperature and experiences a cooling rate sufficient to produce martensite. Closer to, but above the band $i+1$ there is sufficient temperature and time during stage 2 to transform the martensitic $\alpha$ into very fine Widmanstätten. In fact, during annealing, martensite decomposes to $\alpha+\beta$ either by $\beta$ particles at dislocations, or $\beta$ layers between $\alpha$ boundaries. ${ }^{[18]}$ In the area between the bands $i$ and $i+1$, coarsening of the very fine Widmanstätten produced during the deposition of layer $i$ occurs, and the pattern shown in Figures 8(d) through 11 is generated. Below band $i$, no significant microstructural changes occur, apart from a possible coarsening of $\alpha$ lamellae which retain the repetitive pattern.

The addition of deformation introduced a small but measurable reduction in the overall size of the $\alpha$ lamellae (Figure 8(d)). There are three reasons for this behavior. Firstly, it could be a consequence of the larger number of grain boundaries. In the case of basketweave or 


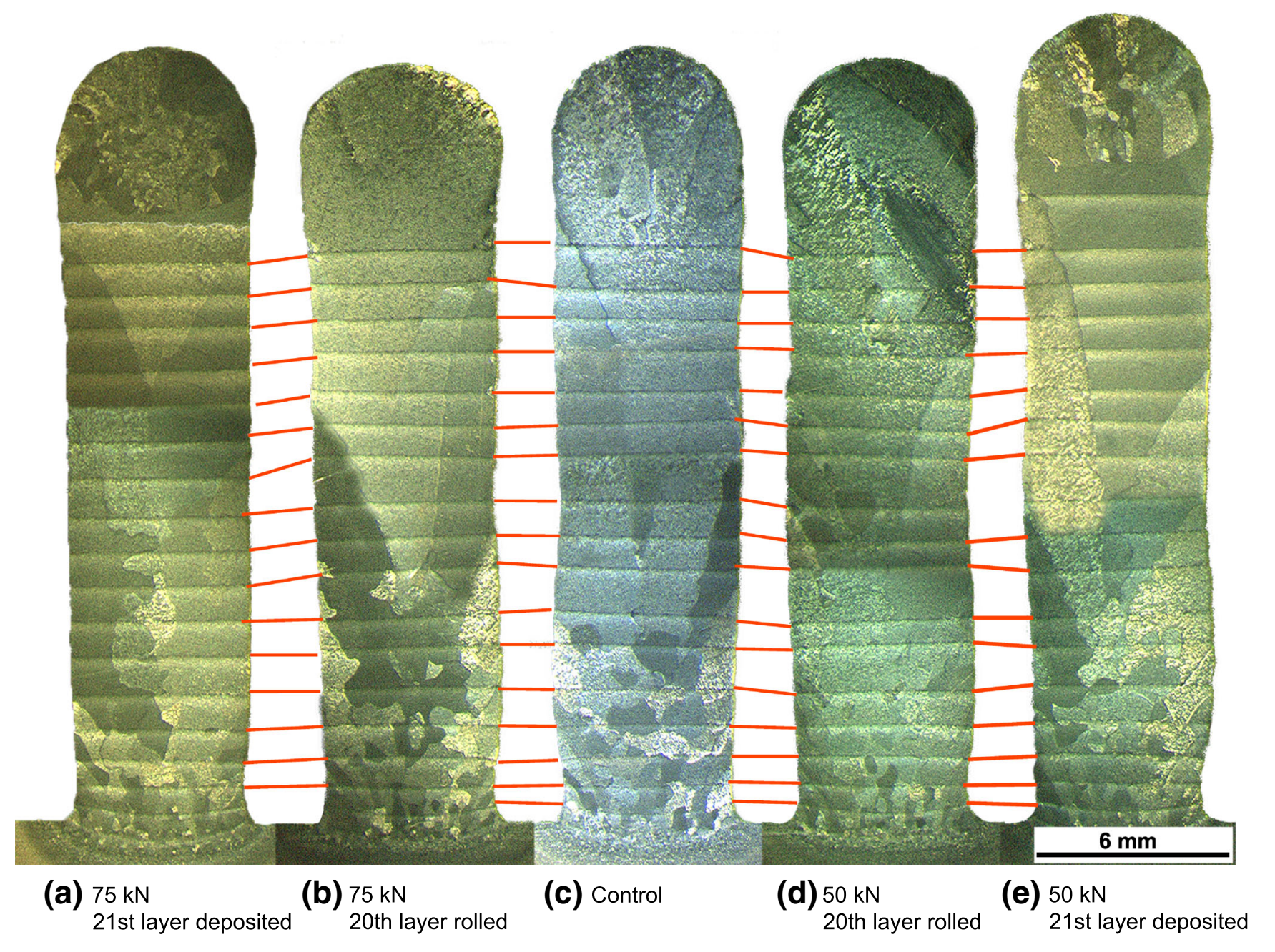

Fig. 13- Optical microscopy images from the fundamental study samples rolled with loads of $(a) 75 \mathrm{kN}$ with subsequent deposited layer, $(b) 75$ $\mathrm{kN},(c)$ control, (d) $50 \mathrm{kN}$, and (e) $50 \mathrm{kN}$ with a subsequent deposited layer.

Widmanstätten microstructures, $\alpha$ colonies nucleate at the grain boundaries and grow perpendicular to them. ${ }^{[18]}$ When $\alpha$ colonies collide with each other, and therefore, cannot grow further, additional colonies start nucleating perpendicular to the side of those which have already developed. In the case of the rolled samples, there were more $\alpha$ phase nucleation sites due to the larger number of prior $\beta$ grains. Therefore, lamellae growth is hindered by their own competition, hence the overall size of the lamellae decreases with the increasing rolling load. However, there is a large difference in the scale of the prior $\beta v s$ the $\alpha$ lamellae thickness $(100 \mu \mathrm{m} v s$ $<1 \mu \mathrm{m}$, respectively) so the influence of this may be limited. An alternative explanation is that deformation influences the transformation of martensitic $\alpha$ to Widmanstätten providing more nucleation sites for the transformation which leads to a finer microstructure. Finally, recrystallization happened at temperatures comparable to those used to achieve a fully equiaxed microstructure during plates production, in which case the $\alpha$ phase equilibrium volume fraction is large enough to stimulate the growth of $\alpha$ phase from the deformed lamellae. ${ }^{[27]}$
At the top of the deposit, there was a region with columnar prior $\beta$ grains which extended approximately $2 \mathrm{~mm}$ (see optical microscopy images in Figures 3 and 14). Although not measured, the boundary with the equiaxed material underneath may correspond closely to the region that was molten during the deposition of the last layer; the solidifying grains grow epitaxially from the material underneath.

\section{Practical Aspects}

High-pressure interpass rolling was performed after the part was allowed to cool down to room temperature. The time taken for the part to cool down and the rolling process itself will affect the productivity of WAAM. However, depositing large parts will extend the cooling time between layers lessening its impact on productivity. In addition, various techniques may be considered for improving process productivity including depositing multiple parts at once, using multiple processing heads, i.e., one for deposition and another for rolling, and cryogenic cooling. Therefore, there are a number of 

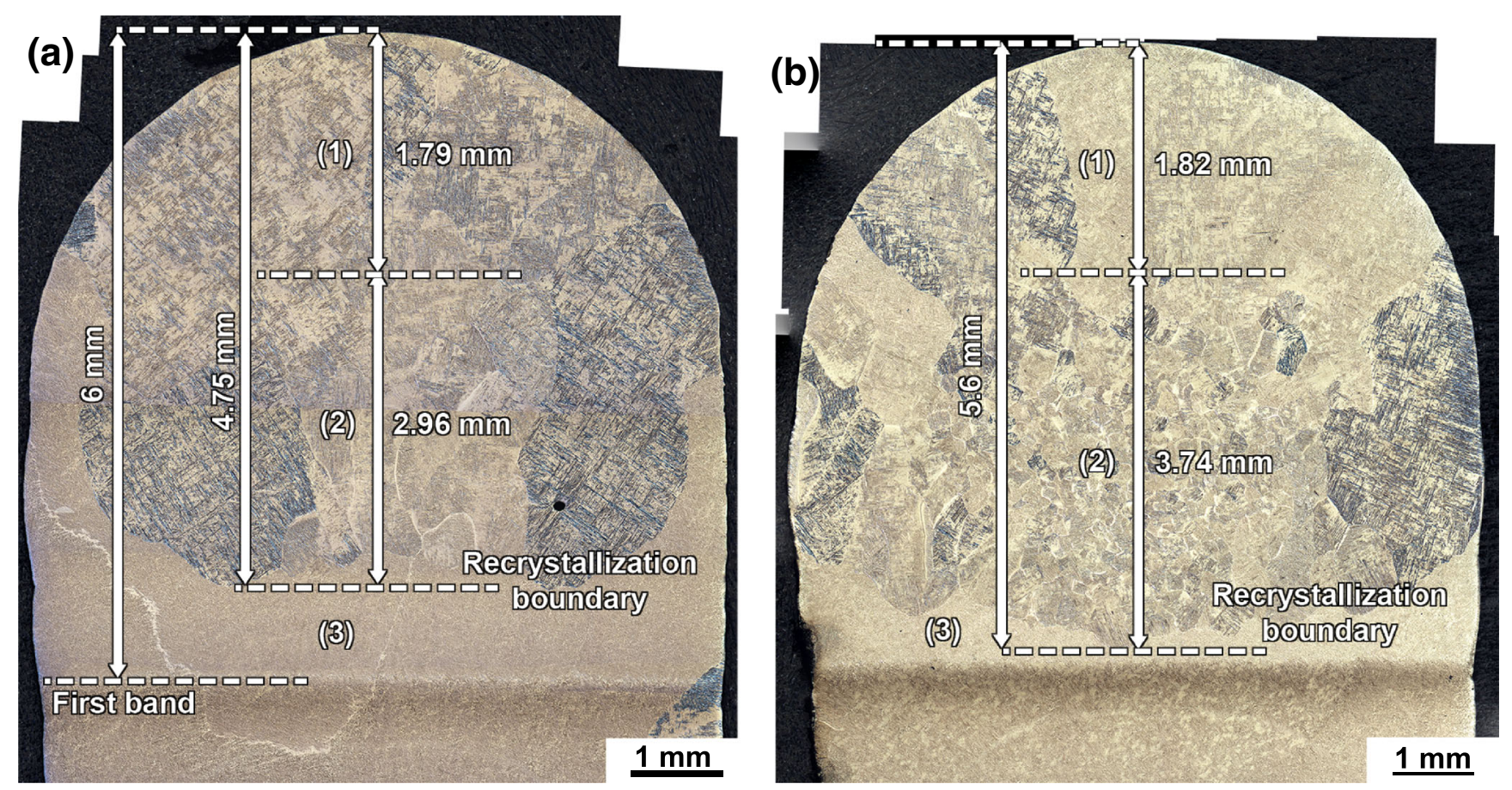

Fig. 14 Optical microscopy images from the fundamental study samples rolled with loads of $(a) 50 \mathrm{kN}$ with subsequent deposited layer, and (b) $75 \mathrm{kN}$ with subsequent deposited layer. (1) indicates the top area with columnar grains, (2) the recrystallized area, and (3) the bulk of the material which did not undergo any recrystallization.

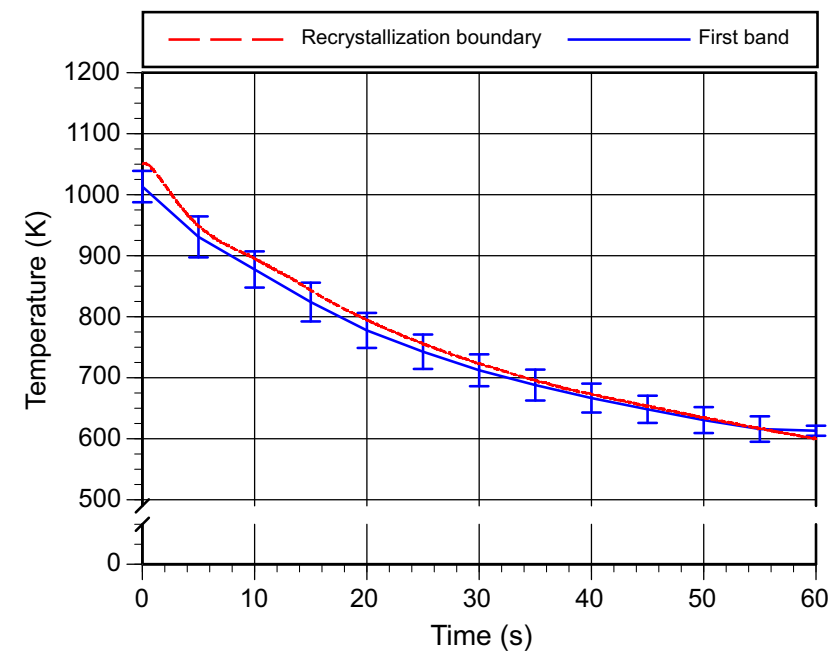

Fig. 15-Thermal history at $5.6 \mathrm{~mm}$ (recrystallization boundary) and $6.0 \mathrm{~mm}$ (first band) below the top of the sample rolled with $75 \mathrm{kN}$ with a subsequent deposited layer.

options to efficiently implement interpass rolling on a production system.

Finally, with regard to the flat roller, this solution is of particular interest because it has a number of practical advantages over the profiled roller: firstly, the shape of the roller is independent of the deposit geometry so a single roller could be used for a variety of wall widths; secondly, most real WAAM parts have intersecting features which cannot be rolled easily with the profiled roller.

\section{CONCLUSIONS}

1. Rolling induced significant prior $\beta$ grain refinement, a reduction in the overall thickness of $\alpha$ phase lamellae, and a modification of the microstructure from strongly columnar to equiaxed. This is due to the recrystallization that occurred when the previously deformed layer was heated during the deposition of the next layer.

2. A fundamental study was used to understand the microstructural changes that occurred during the process. The last layer of an "unrolled" control sample was rolled after which a new layer was deposited. The size of the recrystallized region was influenced by the load and hence the extent of deformation in the material. In addition, the temperature of the recrystallized region boundary and first microstructural band were $1053 \mathrm{~K}$ and $1013 \mathrm{~K}\left(780{ }^{\circ} \mathrm{C}\right.$ and $\left.740{ }^{\circ} \mathrm{C}\right)$, respectively, below the $\beta$ transus and very close to the $\alpha$ dissolution temperature of $1021 \mathrm{~K}\left(748^{\circ} \mathrm{C}\right)$.

3. The flat roller, which has significant practical advantages, provided similar reductions in prior $\beta$ grain size and may be the preferred choice for commercial exploitation of the process.

\section{ACKNOWLEDGMENTS}

The authors would like to thank Mr. Flemming Nielsen and Mr. Brian Brooks for their help during the experimental work. Mr. Andrew Dyer's and Dr. Xianwei Liu's assistance during the optical and scanning 
electron microscopy images analysis was greatly appreciated. Jack Donoghue provided valuable assistance for the grain size analysis. The financial support from the Engineering and Physical Sciences Research Council under Grant No. EP/K029010/1 and Airbus Group Innovations is acknowledged. Enquiries for access to the data referred to in this article should be directed to researchdata@cranfield.ac.uk.

\section{OPEN ACCESS}

This article is distributed under the terms of the Creative Commons Attribution 4.0 International License (http://creativecommons.org/licenses/by/4.0/), which permits unrestricted use, distribution, and reproduction in any medium, provided you give appropriate credit to the original author(s) and the source, provide a link to the Creative Commons license, and indicate if changes were made.

\section{REFERENCES}

1. S. Herranz, F.J. Campa, L.N.L. de Lacalle, A. Rivero, A. Lamikiz, E. Ukar, J.A. Sánchez, and U. Bravo: Proc. of the Instit. of Mech. Eng., Part B.J Eng. Manufact, vol. 219, 2005, pp. 789-801.

2. F. Martina, J. Mehnen, S.W. Williams, P. Colegrove, and F. Wang: J. Mater. Process. Technol., 2012, vol. 212, pp. 1377-86.

3. S.W. Williams, F. Martina, A.C. Addison, J. Ding, G. Pardal, and P. Colegrove: Mater. Sci. Technol.. DOI:10.1179/1743284 715Y.0000000073, 2015.

4. F. Wang, S. Williams, P. Colegrove, and A.A. Antonysamy: Metall. Mater. Trans. A, 2013, vol. 44A, pp. 968-77.

5. B. Baufeld, O. Van der Biest, and R. Gault: Mater. Des., 2009, vol. Suppl.1, pp. S106-11.

6. P.S. Almeida and S. Williams: 21st Intern. Solid Freeform Fabrication Symp., Austin, TX, pp. 25-36.

7. S. Kurkin and V. Anufriev: Weld. Prod., 1984, vol. 31, pp. 32-34.
8. J. Altenkirch, A. Steuwer, P.J. Withers, S.W. Williams, M. Poad, and S.W. Wen: Sci. Technol. Weld. Join., 2009, vol. 14, pp. 185-92.

9. P.A. Colegrove, H.E. Coules, J. Fairman, F. Martina, T. Kashoob, H. Mamash, and L.D. Cozzolino: J. Mater. Process. Technol., 2013, vol. 213, pp. 1782-91.

10. P.A. Colegrove, F. Martina, M.J. Roy, B. Szost, S. Terzi, S.W. Williams, P.J. Withers, and D. Jarvis: Adv. Mater. Res., 2014, vol. 996, pp. 694-700.

11. F. Martina, S. Williams, and P.A. Colegrove: 24th Intern. Solid Freeform Fabrication Symp., Austin, TX, pp. 490-96.

12. ASTM E112-96: Standard Test Methods for Determining Average Grain Size, 2004.

13. J. Tiley, T. Searles, E. Lee, S. Kar, R. Banerjee, J.C. Russ, and H.L. Fraser: Mater. Sci. Eng. A Struct., 2004, vol. 372, pp. 191-98.

14. Adobe Photoshop CS4, http://www.adobe.com/products/ photoshopfamily.html, 2008.

15. ASTM E1382-1997: Standard Test Methods for Determining Average Grain Size Using Semiautomatic and Automatic Image Analysis, 1997.

16. ImageJ: http://rsbweb.nih.gov/ij/index.html, 2012.

17. Measure Roi PA: http://www.optinav.com/Measure-Roi.htm, 2012.

18. G. Lütjering and J. Williams: Titanium, 2nd ed., Springer, New York, 2007, pp. 29-33.

19. R. Contieri, M. Zanotello, and R. Caram: Mater. Sci. Eng. A Struct., 2010, vol. 527, pp. 3994-4000.

20. C. Xue, J. Hu, G. Chen, W. Zhou, and J. Zhang: Rare Met. Mater. Eng., 2012, vol. 41, pp. 472-76.

21. T. Seshacharyulu, S. Medeiros, W. Frazier, and Y. Prasad: Mater. Sci. Eng. A Struct., 2000, vol. 284, pp. 184-94.

22. P.A. Colegrove, J. Ding, M. Benke, and H.E. Coules: Math. Model. Weld Phenom., 2012, vol. 10, pp. 691-702.

23. S. Kelly and S. Kampe: Metall. Mater. Trans. A, 2004, vol. 35A, pp. 1869-79.

24. J.W. Elmer, T.A. Palmer, and J. Wong: J. Appl. Phys., 2003, vol. 93, pp. 1941-47.

25. S. Kelly and S. Kampe: Metall. Mater. Trans. A, 2004, vol. 35A, pp. 1861-67.

26. F. Gil, M. Ginebra, J. Manero, and J. Planell: J. Alloys Compd., 2001, vol. 329, pp. $142-52$.

27. G. Lütjering: Metall. Mater. Trans. A, 1998, vol. 243A, pp. $32-45$. 